\title{
A Role for Cell Polarity in Lifespan and Mitochondrial Quality Control in the Budding Yeast Saccharomyces cerevisiae
}

Emily J. Yang**, Wolfgang M Pernice ${ }^{{ }^{+}}$and Liza A. Pon*

*Department of Pathology and Cell Biology, Columbia University, New York, NY 10032

${ }^{\wedge}$ current address: Department of Neurology, Columbia University, New York, NY 10032

${ }^{+}$EJY and WMP contributed equally to these studies

Correspondence: L.A.P (lap5@cumc.columbia.edu)

Keywords: aging, replicative lifespan, asymmetric cell division, bud site selection, mitochondrial inheritance, cytoskeleton, budding yeast, Saccharomyces cerevisiae 
Budding polarity declines with age

Polarized Mfb1p localization declines with age

Deleting bud site selection gene BUD1/RSR1 disrupts polarized Mfb1p localization and mitochondrial distribution

Loss of bud site selection results in reduced mitochondrial function, replicative lifespan and cellular healthspan8

BUD1 and MFB1 act in the same pathway to regulate mitochondrial quality and lifespan

DISCUSSION

Age-associated declines in polarity site selection in yeast

Age-associated declines in Mfb1p localization and function in mitochondrial quality control

Role for the polarity machinery in lifespan control in yeast

Is the mother distal tip the posterior pole during asymmetric cell division in haploid yeast?

ACKNOWLEDGMENTS

AUTHOR CONTRIBUTIONS

DECLARATION OF INTERESTS

Figure 1. Polarized bud site selection declines as yeast cells age.

Figure 2. Polarized distribution of Mfb1 $p$ and mitochondria decline with age.

Figure 3. Deletion of BUD1 results in depolarized localization of $\mathrm{Mfb} 1 \mathrm{p}$, defects in mitochondrial distribution, decreased mitochondrial quality and reduced RLS.

Figure 4. BUD1 and MFB1 function in the same pathway for mitochondrial distribution and quality control and

RLS.

Supplemental Figure 1. Isolation of cells of defined replicative age using a Miniature Chemostat Aging Device. 21 Supplemental Figure 2. Mfb1p co-localizes with mitochondria during the entire lifespan in yeast. 22 Supplemental Figure 3. Deletion of MFB1 has no effect on polarized bud site selection. 23 Supplemental Figure 4. Mfb1p co-localizes with mitochondria in bud1A.

STAR METHODS

Yeast Growth Conditions $\quad 25$

$\begin{array}{ll}\text { Yeast Strain Construction } & 25\end{array}$

Microscopy $\quad 26$

Visualization of Bud Scars $\quad 27$

Enrichment of Aged Cells $\quad 27$

Enrichment of aged cells in the miniature-Chemostat Aging Device and assessment of bud site selection 28

Analysis of Mitochondrial and Mfb1p Distribution $\quad 29$

Analysis of Co-localization of Mfb1p and Mitochondria $\quad 30$

Analysis of Mitochondrial Redox State $\quad 30$

Analysis of Replicative Lifespan $\quad 31$

Quantification and Statistical Analysis $\quad 31$

STRAINS USED IN THIS STUDY: $\quad 32$

PLASMIDS USED IN THIS STUDY:

PRIMERS USED IN THIS STUDY: $\quad 33$

STAR+METHODS KEY RESOURCES TABLE

$\begin{array}{lc}\text { REFERENCES } & 37\end{array}$ 


\section{Summary}

Babies are born young, largely independent of the age of their mothers. Mother-daughter age asymmetry in yeast is achieved, in part, by inheritance of higher-functioning mitochondria by daughter cells and retention of some high-functioning mitochondria in mother cells. The mitochondrial F-box protein, Mfb1p, tethers mitochondria at both poles in a cell cycle-regulated manner: it localizes to and anchors mitochondria to the mother cell tip throughout the cell cycle, and to the bud tip prior to cytokinesis. Here, we report that cell polarity and polarized localization of Mfb1p decline with age in S. cerevisiae. Moreover, deletion of BUD1/RSR1, a Ras protein required for cytoskeletal polarization during asymmetric yeast cell division, results in depolarized Mfb1p localization, defects in mitochondrial distribution and quality control, and reduced replicative lifespan. Our results demonstrate a role for the polarity machinery in lifespan through modulating Mfb1 function in asymmetric inheritance of mitochondria during yeast cell division. 


\section{Introduction}

Generation of cellular asymmetry is essential for asymmetric cell division in metazoans, unicellular eukaryotes and prokaryotes (Soares et al., 2013). Mitochondria are a cell fate determinant and are differentially segregated during this process in stem cells and budding yeast. Indeed, new and old mitochondria are segregated during division of human mammary stem-like cells. The daughter cell that preferentially inherits new mitochondria retains stem cell properties, while the daughter that inherits old mitochondria becomes a tissue progenitor cell (Katajisto et al., 2015). Similarly, in the budding yeast, Saccharomyces cerevisiae, the daughter cell or bud inherits fitter mitochondria that are more reduced, have lower reactive oxygen species levels (ROS) and higher membrane potential $(\Delta \psi)$. This in turn, allows daughter cells to live a full lifespan, while mother cells, which inherit lower-functioning mitochondria, continue to age (Higuchi et al., 2013; McFaline-Figueroa et al., 2011).

During polarity establishment in C. elegans, Drosophila and mammalian systems, polarity determinants and their targets are asymmetrically distributed to the anterior and posterior poles. The bud tip is analogous to the anterior pole during early stages of polarized growth and asymmetric cell division in yeast. Activation of Bud1p/Rsr1p (a Ras-like GTPase) at the presumptive bud site results in recruitment of Cdc24p to that site (Zheng et al., 1995), which in turn results in site-specific activation of Cdc42p. Activated Cdc42p initiates reorganization of the cytoskeleton, assembly of actin cables at the bud tip, and actin cable-driven transport of all cellular constituents to the bud for bud formation and growth (Fehrenbacher et al., 2004; Moseley and Goode, 2006). Polarized actin cables also transport and further enrich Cdc42p at the selected anterior pole (Slaughter et al., 2009). Finally, actin cables enable segregation of mitochondria in dividing yeast by mediating 1) preferential transport of higher-functioning mitochondria from the mother cell to the anterior pole (Higuchi et al., 2013) and 2) transport of one of the tethers (Mmr1p) that anchors and retains those higher-functioning mitochondria at the bud tip (Shepard et al., 2003; Swayne et al., 2011). Indeed, promoting actin cable function in asymmetric mitochondrial inheritance during cell division promotes daughter cell fitness and extends lifespan in yeast (Higuchi et al., 2013).

Emerging evidence indicates that the tip of the mother cell that is distal to the bud is the posterior pole during polarized cell division in haploid yeast cells. Specifically, a small population of mitochondria that are associated with the mitochondrial F-box protein, Mfb1p, are anchored at 
and accumulate in the mother cell tip (Pernice et al., 2016; Yang et al., 1999). Mfb1p was originally identified as a non-canonical F-box protein that localizes to mitochondria and is required for normal mitochondrial distribution (Dürr et al., 2006; Kondo-Okamoto et al., 2006). Our studies indicate that mitochondria that are anchored in the mother cell tip are higher functioning compared to other mitochondria in the mother cell and revealed a role for Mfb1p as a cell cycle-regulated tether that anchors mitochondria at the mother cell tip throughout the cell cycle and at the bud tip immediately before cytokinesis (Pernice et al., 2016). Importantly, deletion of MFB1 results in defects in anchorage of mitochondria, reduced mitochondrial function throughout the cell and premature aging (Pernice et al., 2016).

Cell polarity during asymmetric cell division in mammalian stem cells declines with age. Specifically, stem cell division becomes more symmetrical in aged mice, indicating a more depolarized phenotype (Florian et al., 2018). Moreover, Cdc42 activity increases with age in hematopoietic stem cells, and inhibiting Cdc42 reduces aging phenotypes in those cells (Florian et al., 2012). By what mechanisms age-linked changes in the polarity machinery affect lifespan, however, remains unclear. Moreover, deletion of BUD1 results in premature aging in yeast (Clay et al., 2014). However, the mechanism underlying Bud1p function in lifespan control is not well understood.

Here, we studied the effect of loss of cell polarity on Mfb1p and Mfb1p functions in mitochondrial quality control and lifespan in yeast. We find that cell polarity, as revealed through bud site selection, declines with age in budding yeast. We also obtained evidence that polarized localization of Mfb1p to the mother cell tip is lost with age, and identify a role for BUD1/RSR1 and the cell polarity machinery in lifespan and mitochondrial quality control through effects on Mfb1p localization.

\section{Results}

\section{Budding polarity declines with age}

One model for the aging process in yeast is replicative lifespan (RLS), a measure of the number of times that a mother cell can divide (Longo et al., 2012). The sites for yeast cell division during this process are determined by polarity cues. One such cue is the bud scar, a chitinous ring on the cell wall of the mother cell that forms where buds separate from mother cells and 
marks the site of cytokinesis. In haploid yeast, polarity proteins are recruited to newly formed bud scars and serve as landmarks to stimulate production of the next bud adjacent to the previous bud site (axial or unipolar budding) (Chant and Pringle, 1995). To determine whether polarity declines with age in yeast, we studied whether bud site selection changes during the aging process.

Yeast of defined replicative age were isolated using a chemostat-based method (Hendrickson et al., 2018). Mid-log phase yeast, which are largely young cells, were immobilized and allowed to undergo replicative aging in a miniature chemostat aging device (mCAD) (Figure 1A). Daughter cells produced from immobilized cells were removed by continuous media exchange. Immobilized cells isolated from mCAD exhibit increasing age and aging phenotypes, including an increase in cell size and decrease in viability, as a function of the time of propagation in mCAD (Figure 1B, Supplemental Figure 1A-C).

In order to assess the fidelity of axial budding, whereby new buds form adjacent to the previous bud site, bud scars were visualized using wheat germ agglutinin (WGA), a chitin-binding agent. Inspired by TrackScar (Maxwell and Magwene, 2017), we sequentially stained yeast bud scars with WGA conjugated to different fluorescent dyes to distinguish new from old bud scars. Cells were first stained with Alexa488-WGA to label all bud scars. They were then propagated for $2 \mathrm{hrs}$ and stained with Alexa594-WGA to label the 2 newest bud scars (Figure 1A). Here, bud site selection was scored as polarized if the 2 newest bud scars were adjacent to each other and random if those bud scars were not adjacent.

We found that bud site selection is polarized in $>97 \%$ of the young cells (1-4 generations) examined. However, loss of budding polarity is evident in $11.0 \%$ of middle-aged cells (5-10 generations) and declined further to $27.7 \%$ and $30.6 \%$ in cells of advanced age, $11-20$ and $>20$ generations, respectively (Figure 1C, D). Thus, polarity establishment during bud site selection declines with age in yeast. Interestingly, the proportion of cells displaying randomized bud-site selection plateaus at ca. $30 \%$ for cells of age 11-20 and beyond.

\section{Polarized Mfb1p localization declines with age}

Next, we tested whether aging affects the function and polarized localization of Mfb1p. We visualized mitochondria and Mfb1p using Cit1p-mCherry (a mitochondrial matrix marker) and Mfb1p-GFPEnvy, respectively, in yeast of defined replicative age. Since Mfb1p localizes to 
mitochondria at the bud tip late in the cell cycle, only cells in early stages of the cell cycle (budto-mother ratios between 0.2-0.6) were included in the quantification. Therefore, the accumulation of mitochondria at the bud tip is not yet evident in the cells analyzed.

We detect co-localization of Mfb1p with mitochondria throughout the aging process in yeast (Figure 2A). Quantitative analysis of co-localization of Mfb1p with mitochondria using Pearson's coefficient and Manders' M1 coefficient indicate that there is no significant difference in the cooccurrence of Mfb1 $\mathrm{p}$ with mitochondria as a function of replicative age (Supplemental Figure 2A and B). Interestingly, we found that Manders' M2 coefficient, co-localization of mitochondria with Mfb1p, gradually increases with age, indicating that the capacity of mitochondria to bind to Mfb1p increases modestly with age.

The overall asymmetric distribution of Mfb1 $\mathrm{p}$ and mitochondria between mother cells and buds also persists throughout the aging process. Prior to cytokinesis, Mfb1p is excluded from buds: $>99 \%$ of Mfb1p-GFPEnvy is present exclusively in the mother cell (Figure 2A-B). Thus, although the mechanism for localization of Mfb1p primarily to mother cells is not well understood, this aspect of Mfb1p asymmetry does not appear to decline with age. Similarly, the distribution of mitochondria between mother cells and early buds persists with age (Figure 2A, C).

In contrast, we find that the localization of Mfb1p and mitochondria within mother cells changes with age (Figure 2A, D-E). Our analysis confirms that Mfb1p and mitochondria accumulate at the distal tip of young mother cells (1-4 generations), which reflects Mfb1p function as a tether for mitochondria in the mother distal tip. However, we detect a decrease in the amount of Mfb1p-GFPEnvy and mitochondria in the mother distal tip and a corresponding increase in Mfb1p-GFPEnvy and mitochondrial levels in the center of the mother cell with increasing age. Thus, although binding of Mfb1p to mitochondria and the overall asymmetric distribution of Mfb1p between mother cells and buds are preserved during the aging process, association of Mfb1p with the mother distal tip and its function as a tether for mitochondria at that site decline with age.

\section{Deleting bud site selection gene BUD1/RSR1 disrupts polarized Mfb1p localization and mitochondrial distribution}

To determine whether the age-linked declines in Mfb1p are due to changes in the cell polarity machinery, we monitored the distribution of Mfb1p and mitochondria in yeast bearing a deletion in the budding polarity gene BUD1. We confirmed that deletion of $B U D 1$ results in random bud 
site selection in haploid yeast cells. On the other hand, deletion of MFB1 does not affect budding polarity (Supplemental Figure 3A-B). Next, we quantified the distribution of Mfb1p-GFP and mitochondria in WT and bud1 $\triangle$ mutant cells. Deleting BUD1 does not affect the steady-state level of Mfb1p (data not shown) or association of Mfb1p with mitochondria (Supplemental Fig. 4). Interesting, deletion of BUD1 also does not affect the global distribution of Mfb1p or of mitochondria between mother cells and buds (Figure 3A-C).

However, loss of axial bud site selection interferes with the localization of Mfb1p at the mother distal tip and tethering of mitochondria at that site (Figure $3 A-C)$. Specifically, we find that deletion of BUD1 results in a decrease in of the relative accumulation of Mfb1p and mitochondria at the mother cell tip, and a compensatory shift of Mfb1p and mitochondrial mass to the mother cell neck in mid-log phase cultures. Nevertheless, mitochondrial tethering to the mother tip is not abolished in bud1 $\Delta$ cells (as it is in $m f b 1 \Delta$ cells), presumably because some Mfb1p localizes to the mother cell tip even in bud1 $\Delta$ cells. Our findings indicate that the asymmetric accumulation of Mfb1p and its function in anchorage of mitochondria in the mother cell tip, but not its binding to mitochondria or global distribution between buds and mother cells, is dependent on Bud1p/Rsr1p.

Loss of bud site selection results in reduced mitochondrial function, replicative lifespan and cellular healthspan

Mfb1p tethers higher-functioning mitochondria at the mother distal tip, which in turn affects mother cell fitness and lifespan (Pernice et al., 2016). Therefore, we tested whether deletion of BUD1 affects mitochondrial function using mitochondria-targeted redox-sensing GFP (mitoroGFP1) (Figure 3D and E). We confirmed that deletion of MFB1 results in reduced mitochondrial function: the ratio of reduced to oxidized mito-roGFP1 in $m f b 1 \Delta$ cells is $20 \%$ lower than that observed in WT cells. Beyond this, we found that mitochondrial redox state in bud1 $\Delta$ cells is $12 \%$ less than that in WT cells but $9.7 \%$ greater than that observed in $m f b 1 \Delta$ cells.

Next, we studied whether deletion of BUD1 affects replicative lifespan (RLS). We find that the mean RLS of WT, bud1 $\Delta$ and $m f b 1 \Delta$ single mutants are $26.7 \pm 7.51,17.15 \pm 4.94$ and $12.1 \pm$ 5.01 generations, respectively. Thus, deletion of BUD1 results in a decrease in RLS. However, the decrease in RLS observed in bud1 $\Delta$ cells is less than that observed in $m f b 1 \Delta$ cells (Figure 3F). Thus, deletion of BUD1 and MFB1 have similar effects on mitochondrial redox state and RLS. 
BUD1 and MFB1 act in the same pathway to regulate mitochondrial quality and lifespan

To investigate whether BUD1 and MFB1 function in the same pathway for control of mitochondrial function and lifespan, we compared the phenotype of bud1 $\Delta \mathrm{mfb} 1 \Delta$ double mutants to that of bud1 $1 \Delta$ or $m f b 1 \Delta$ single mutants. We observed a decrease in mitochondrial content in the mother cell tip and an accumulation of mitochondria at the mother cell neck in each of these strains. Moreover, the changes in mitochondrial distribution in the $m f b 1 \Delta$ single mutant are similar to those observed in the bud1 $\Delta m f b 1 \Delta$ double mutant (Figure 4A-C). Analysis of mitochondrial quality revealed that the redox state of mitochondria in bud1 $\Delta \mathrm{mfb} 1 \Delta$ cells is lower than that in WT and bud1 $\Delta$ cells, but similar to that observed in $m f b 1 \Delta$ cells (Figure $4 D-E$ ). Finally, we found that the RLS of the bud1 $1 \mathrm{mfb} 1 \Delta$ double mutant is similar to that of the $m f b 1 \Delta$ single mutant (Figure 4F-G). Thus, the defects in mitochondrial distribution and function as well as RLS in the bud1 $\Delta m f b 1 \Delta$ double mutant are similar to those observed in the $m f b 1 \Delta$ single mutant, and are not additive. These findings provide genetic evidence that MFB1 and BUD1 function in the same pathway for control of mitochondrial distribution and quality control and for replicative lifespan in yeast.

\section{Discussion}

Aging is inevitable and negatively impacts numerous organismal functions, one of the most basic of which is cellular polarity. One of the manifestations of polarity establishment in budding yeast is selection of a site for bud formation during asymmetric cell division. Here, we provide evidence that bud site selection fidelity declines with age. Moreover, we demonstrate that another highly polarized phenomenon, Mfb1p-mediated mitochondrial inheritance, also decreases as a function of age. We found that disabling the bud site selection machinery alters the polarized localization of Mfb1p at the mother distal tip, and compromises Mfb1p's function in mitochondrial distribution, mitochondrial quality and lifespan control. Finally, we obtained evidence that Mfb1p is a target for the machinery for polarized bud site selection. Together, these findings support a model in which budding polarity contributes to lifespan control through regulating the function of Mfb1p. 
Cellular aging impacts the cell polarity machinery in yeast and other cells. For example, cell division becomes more symmetric with replicative age in yeast, which leads to premature aging in daughter cells (Kennedy et al., 1994). Moreover, early evidence indicated that polarized bud site selection may decline with age (Jazwinski et al., 1998). However, resolution of bud site selection was limited in early studies. We revisited this topic using approaches for more effective, non-invasive isolation of yeast of different replicative ages and for visualization of individual bud site selection events during the aging process with greater temporal resolution. Our studies provide definitive evidence that polarized bud site selection declines with age in yeast.

Our study also demonstrates that the decline in budding polarity in aging yeast is not linear. The bud site selection machinery is robust in younger cells (1-5 generations). This is expected since stringent bud site selection is evident in mid-log phase yeast, which are primarily young cells. However, we detect a significant increase in random bud site selection in older cells ( $>5$ generations). Interestingly, the decline in axial bud site selection reaches a plateau at 10-20 generations and does not decline further as cells age.

Previous studies indicate that a cell that undergoes random budding events can exhibit polarized bud site selection at subsequent rounds of cell division (Jazwinski et al., 1998). This finding raises the possibility that the polarity of bud site selection is not lost irrevocably with age. Rather, the stringency of this process may decline with age. The plateau in polarized bud site selection observed in yeast at advanced age may be a consequence of the reduced stringency of this aspect of polarity establishment in yeast.

\section{Age-associated declines in Mfb1p localization and function in mitochondrial quality control}

Our previous studies revealed that Mfb1p functions as a tether that anchors a small population of higher-functioning mitochondria in the mother cell tip, and that this process is required to retain some higher-functioning mitochondria in mother cells, which in turn is required for mother cell fitness and lifespan (Pernice et al., 2016). Our previous studies also revealed an age-linked decline in mitochondrial function in yeast (McFaline-Figueroa et al., 2011) and that defects in mitochondrial quality control can result in premature aging in yeast (Higuchi et al., 2013). Here, we find that Mfb1p function in binding to mitochondria does not decline with age. However, we detect an age-associated decline in Mfb1p's function as a mitochondrial tether and 
in mitochondrial quality control: accumulation of Mfb1p and mitochondria in the mother cell tip of yeast diminishes as they age.

This age-linked decrease in polarized Mfb1p localization and function may have complex effects on lifespan control. Defects in retention of higher-functioning mitochondria in mother cells may promote daughter cell fitness and mother-daughter age asymmetry by allowing for inheritance of more higher-functioning mitochondria by daughter cells. However, it will also result in depletion of healthy mitochondria from, and premature aging of, mother cells. This, in turn, will reduce the quality of mitochondria that are inherited by subsequent daughter cells produced from the same mother cell and may thereby reduce daughter cell and population fitness. Indeed, deletion of MFB1 results in reduced lifespan (Pernice et al., 2016). Thus, the observed decline in Mfb1p function in mitochondrial quality control may contribute to cellular aging phenotypes, without severely affecting asymmetric inheritance of mitochondria during polarity growth and cell division in yeast.

\section{Role for the polarity machinery in lifespan control in yeast}

Bud1p/Rsr1p, a Rho-GTPase family protein, is a core component of the cell polarity machinery that is essential for polarized bud site selection in yeast. Polarized bud site selection may promote colony expansion in diploid yeast or mating in haploid yeast (Wang et al., 2017). Bud1p is also required for formation of a diffusion barrier at the bud neck, which prevents inheritance of damaged proteins by yeast daughter cell and contributes to mother-daughter age asymmetry (Clay et al., 2014). Finally, deletion of BUD1 results in reduced replicative and chronological lifespan in yeast (Campos et al., 2018; Clay et al., 2014).

However, the mechanistic underpinnings of polarized bud site selection in lifespan control are not well understood. Indeed, there are mechanisms in place that allow budding yeast cells to break symmetry and undergo polarized growth and cell division in the absence of spatial cues or BUD1-mediated bud site selection (Bi and Park, 2012; Slaughter et al., 2009; Wu and Lew, 2013). Moreover, although deletion of BUD1 suppresses the toxic effect of accumulated misfolded proteins, reduced lifespan in bud1 $\Delta$ cells is not due to Bud1p function in production of a diffusion barrier at the bud neck (Clay et al., 2014; Jazwinski et al., 1998). 
Our findings support a role for polarized bud site selection in yeast lifespan control through effects on Mfb1p-dependent mitochondrial quality control. Specifically, we find that deletion of BUD1 results in depolarization of Mfb1p (i.e. defects in localization of Mfb1p to the mother distal tip), defects in anchorage of mitochondria at that site and a decrease in mitochondrial function throughout yeast cells. Moreover, we obtained genetic evidence that BUD1 and MFB1 function in the same pathway for mitochondrial distribution and quality control and on lifespan: deletion of either gene produces similar effects on mitochondrial function and RLS, and deletion of both genes has no detectable additive effect on those phenotypes compared to $m f b 1 \Delta$ or bud1 $\Delta$ single mutants.

Thus, we obtained the first evidence that reduced lifespan produced by loss of polarized bud site selection is due to effects on Mfb1p function in mitochondrial quality control. Moreover, since defects in spindle pole body inheritance late in the cell cycle also results in mislocalization of Mfb1p, defects in mitochondrial quality may contribute to premature aging in yeast with defects in the spindle positioning checkpoint (Manzano-López et al., 2019). Finally, although there is an established link between cellular polarity and aging (Budovsky et al., 2011; Carolina Florian and Geiger, 2010; Soares et al., 2013), it was not clear whether declines in cell polarity are a cause or consequence of aging. Our findings fill this gap and supports a causative role for cell polarity in the aging process.

Is the mother distal tip the posterior pole during asymmetric cell division in haploid yeast?

During establishment of cell polity, asymmetric cues lead to reorganization of the cytoskeleton and polarized localization of cortical proteins at anterior and posterior poles of the cell in response to polarity cues. Diploid yeast exhibit bipolar budding patterns (i.e. bud site selection either adjacent to or at opposite poles from the previous bud site) and asymmetric distribution of polarity factors at anterior and posterior poles of the cell (Chant and Pringle, 1991; Chiou et al., 2017; Kang et al., 2004). However, haploid yeast undergoes axial or unipolar bud site selection: each new bud is produced adjacent to the previous bud site. The bud tip is an established anterior pole and site for activation of polarity factors including Cdc42p and its effectors in haploid and diploid yeast. However, there is no obvious localization of polarity factors to a posterior pole in a haploid yeast cell. 
Mfb1p is the only protein that localizes to the mother cell tip throughout the cell cycle. Moreover, it functions in tethering higher functioning mitochondria in the mother cell tip, which is essential for yeast cell fitness and lifespan. Our finding that Mfb1p is also a target for the machinery for polarized bud site selection raises the possibility that the mother cell tip is the posterior pole during polarized growth and cell division in haploid yeast cells.

\section{Acknowledgments}

We thank members of the Pon laboratory for technical assistance and valuable discussion. This work was supported by awards from the National Institutes of Health (NIH) (GM45735, GM122589, and AG051047) to L.A.P. We also thank Dr. Theresa Swayne in the Confocal and Specialized Microscopy Shared Resource for valuable discussion. The Confocal and Specialized Microscopy Shared Resource in the Herbert Irving Comprehensive Cancer Center at Columbia University is supported in part by an award from the $\mathrm{NIH} / \mathrm{NCl}$ (P30 CA13696).

\section{Author Contributions}

EJY: conceptualization, formal analysis, investigation, validation, writing - original draft, review and editing; WMP: conceptualization, formal analysis, investigation, writing - review and editing; LAP: conceptualization, funding acquisition, supervision, writing - review and editing.

\section{Declaration of Interests}

The authors declare no competing interests. 


\section{Figures}

Figure 1. Polarized bud site selection declines as yeast cells age.

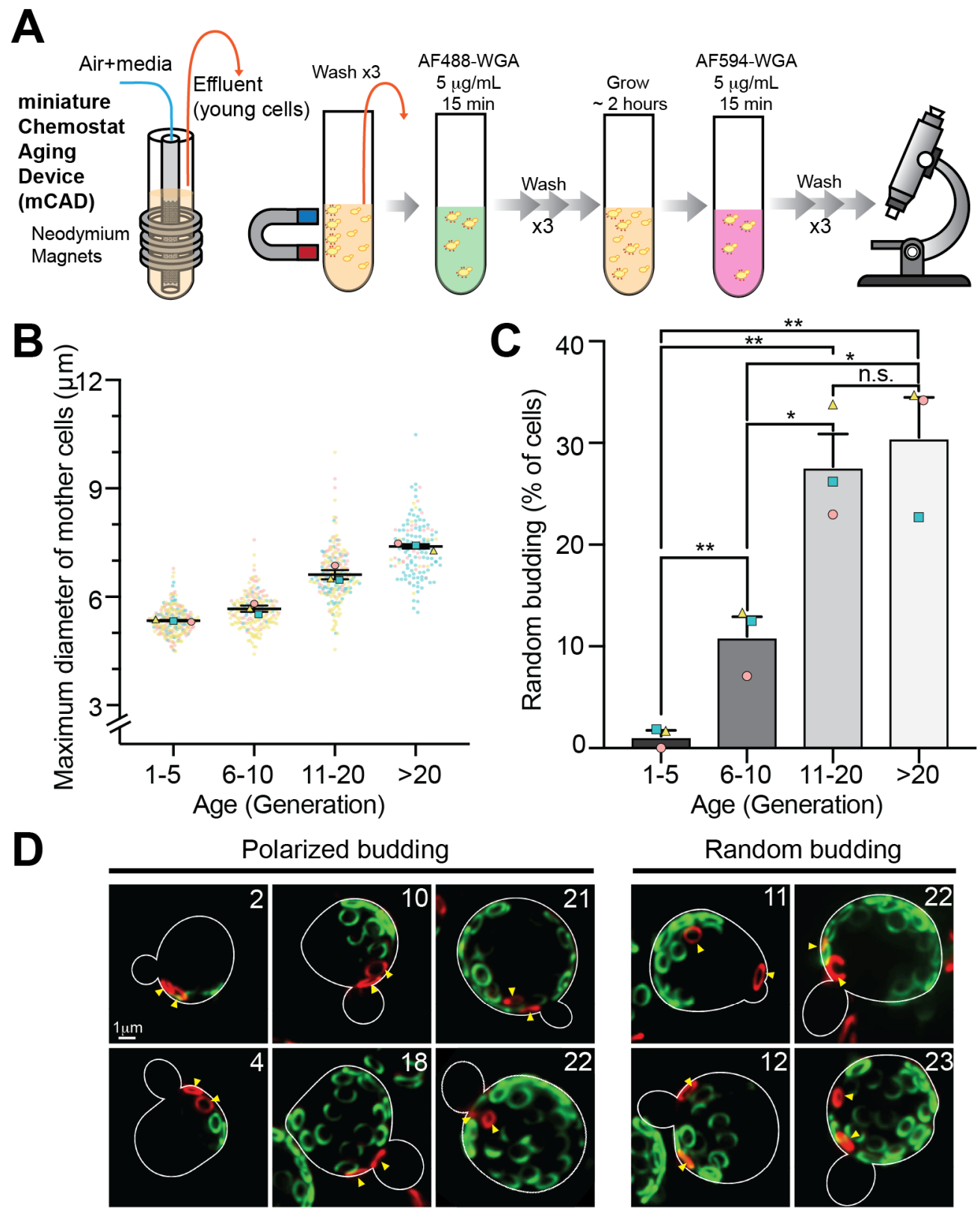

Figure 1. Polarized bud site selection declines as yeast cells age. (A) Illustrations of the miniature chemostat aging device (mCAD) used to isolate cells of different replicative age (left) and the approach used to monitor budding polarity with age by labeling older bud scars with Alexa488-WGA and the 2 newest bud scars with Alexa594-WGA (right). (B) Quantification of cell diameter as a function of time of propagation in $\mathrm{MCAD}$ and replicative age. The diameter measured was the longest axis of the mother 
bioRxiv preprint doi: https://doi.org/10.1101/2021.09.30.462607; this version posted September 30, 2021. The copyright holder for this preprint (which was not certified by peer review) is the author/funder, who has granted bioRxiv a license to display the preprint in perpetuity. It is made available under aCC-BY-NC-ND 4.0 International license.

cell. (C) Quantification of percentage of cells with random bud site selection. $\mathrm{n}=3$ independent trials. > 50 cells/age group/trial. The unpaired two-tailed t test was used for statistical analysis. (D) Representative images of the budding pattern of cells of different replicative age. Replicative age (number in right corner of each image) was determined by scoring the number of WGA-stained bud scars. Older bud scars were labeled with Alexa488-WGA (green). Yellow arrowheads: new Alexa594-WGA-stained bud scars (red). 
Figure 2. Polarized distribution of $\mathrm{Mfb} 1 \mathrm{p}$ and mitochondria decline with age.

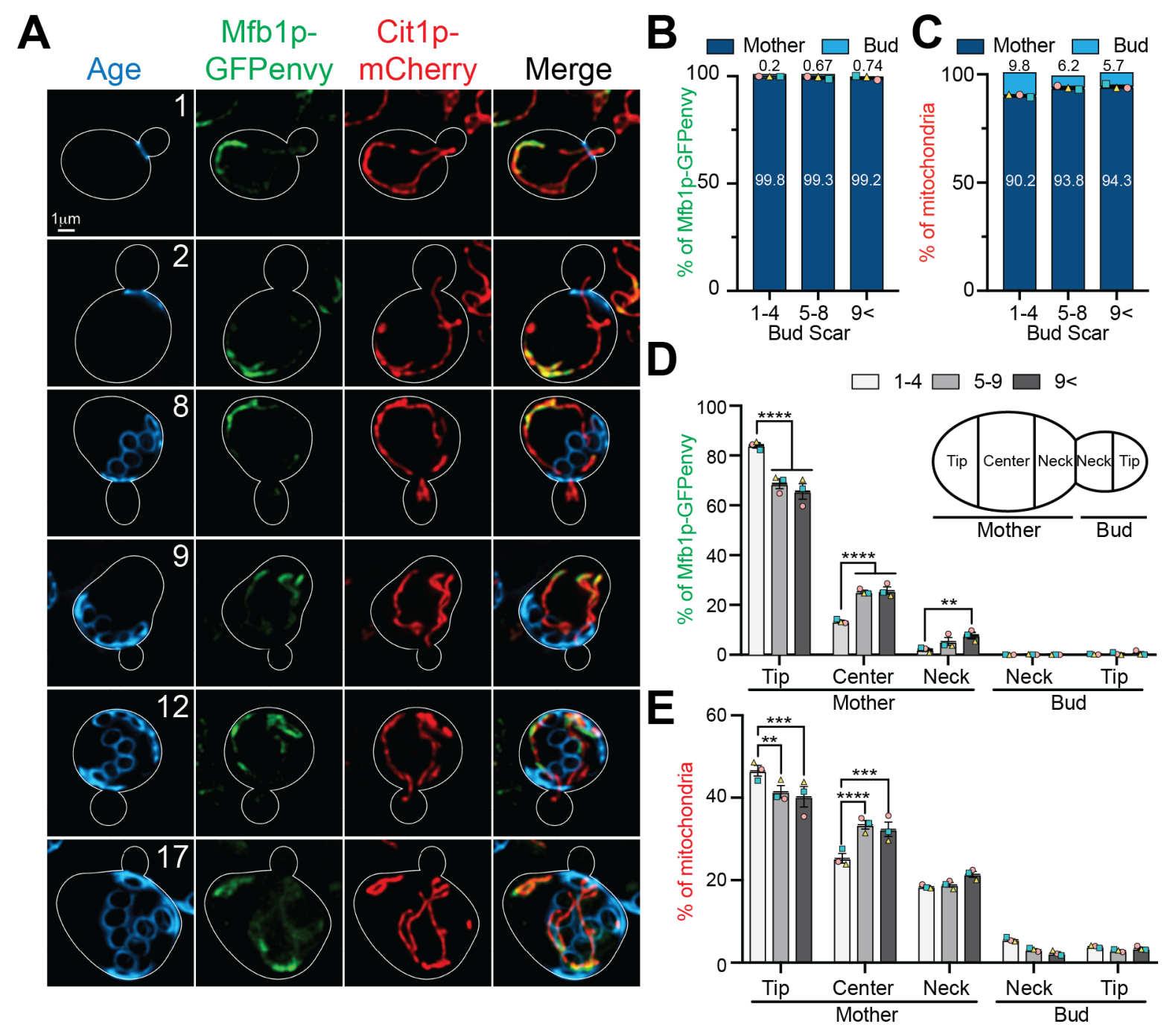

Figure 2. Polarized distributions of Mfb1p and mitochondria decline with age. (A) Maximum projections of Mfb1p and mitochondria in cells during the aging process. The replicative age was determined by scoring calcofluor white-stained bud scars (blue). Mitochondria and Mfb1p were visualized by tagging the mitochondrial marker protein Cit1p with mCherry (red) and Mfb1p with GFP (green). Cell outlines: white. Scale bars: $1 \mu \mathrm{m}$. (B, C, D, E) Distribution of Mfb1p and mitochondria quantified by measuring the integrated fluorescence in 5 regions of interest (ROIs) defined at the upper right panel (D). Cells were grouped according to age: 1-4, 5-9, and $>9$ generations ( $n>49,72$, and 31 cells, respectively, in 3 independent trials. (B-C) Quantification of the distribution of Mfb1p-GFPenvy and mitochondria, respectively, in mother cells and buds. (D-E) Distribution of Mfb1p-GFPenvy and mitochondria, respectively, as a function of replicative age. $p<0.0001$ (one-way ANOVA with Tukey's multiple comparisons test). ROIs are defined as for Fig.2D. 
Figure 3. Deletion of BUD1 results in depolarized localization of Mfb1p, defects in mitochondrial distribution, decreased mitochondrial quality and reduced RLS.

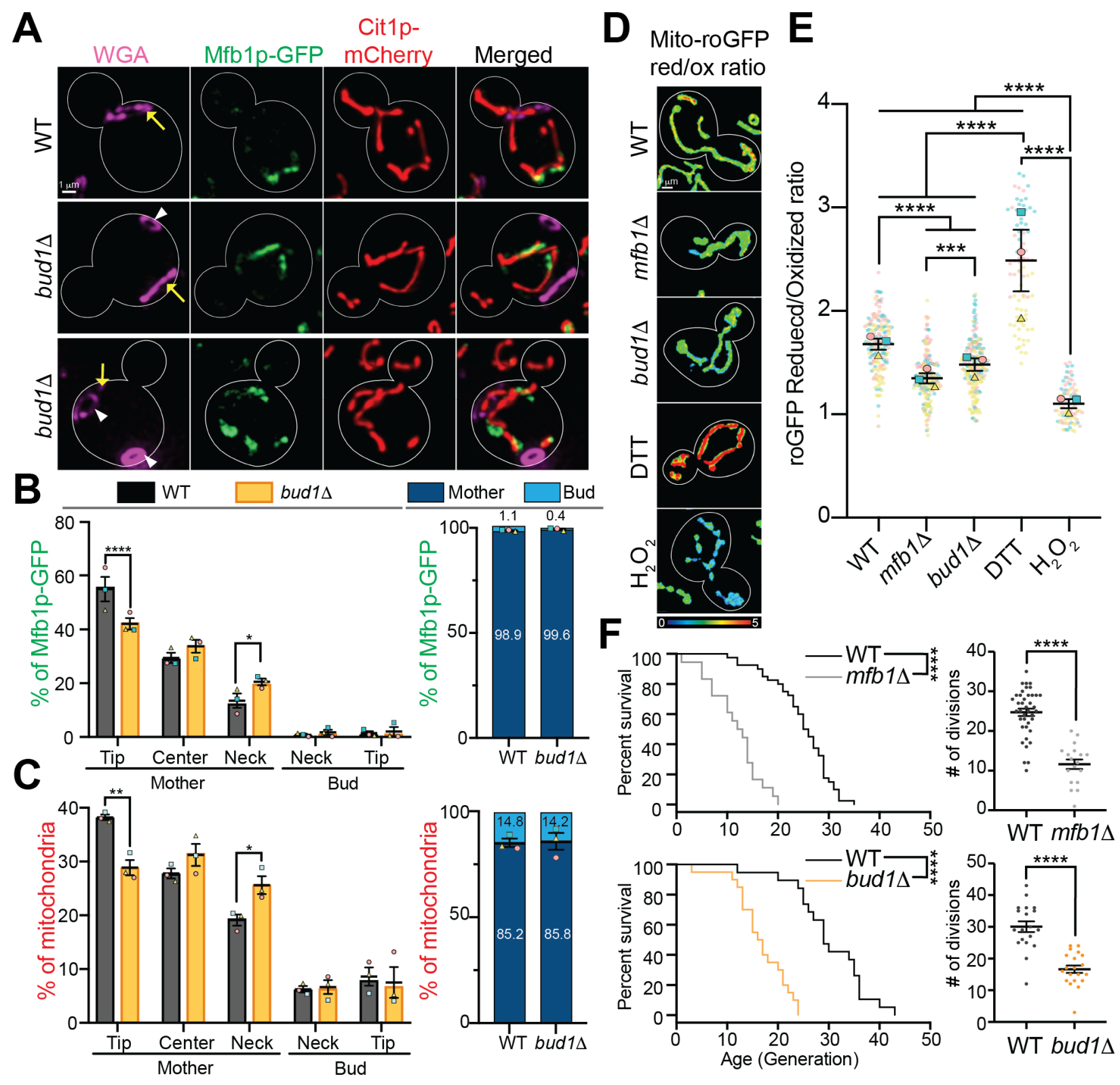

Figure 3. Deletion of BUD1 results in depolarized localization of Mfb1p, defects in mitochondrial distribution, decreased mitochondrial quality and reduced RLS. (A) Representative images of Mfb1p (green) and mitochondria (red) in mid-log phase WT or bud1D cells visualized as for Fig. 2D. The budding pattern was determined by staining birth and bud scars with Alexa647-WGA. Cell outlines: white. Yellow arrows: birth scars. White arrowheads: bud scars. Scale bars: $1 \mu \mathrm{m}$. (B, C) ROIs are defined as for Fig. $1 \mathrm{~B}$. $p<0.0003$ (one-way ANOVA with Tukey's multiple comparisons test). $\mathrm{n}>200$ cells/strain/trial. The mean of 3 independent trials is shown with differently shaped and colored symbols for each trial. (B-C) Relative distribution of Mfb1p-GFP and mitochondria in WT and bud1 1 cells at specific regions within the cell (left 
panels) or in mother cells and buds (right panels). (D) Maximum projections of ratiometric images of reduced/oxidized integrated mito-roGFP1 in mid-log phase WT, $m f b 1 \Delta$, and bud1 $\Delta$ cells. DTT and $\mathrm{H}_{2} \mathrm{O}_{2}$ treated WT cells were controls and illustrate the dynamic range of mito-roGFP1. Colors reflect the intensity of the ratio of reduced-to-oxidized mito-roGFP1 (scale at the bottom.) Cell outlines: white. $n$ $>170$ cells. (E) Quantification of reduced/oxidized mito-roGFP1 of mitochondria in mother cells of genotypes or treatments shown in (D). The means of 3 independent trials are shown, with differently shaped and colored symbols for each trial. Mean of the ratio of reduced/oxidized mito-roGFP1: $1.678 \pm$

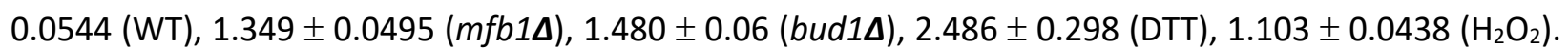
(F) Left: Kaplan-Meier survival plot of replicative lifespans (RLS) of WT (black line), $m f b 1 \Delta$ (grey line) and bud1د (orange line) were measured by counting the number of daughter cells produced from virgin mother cells. Data shown here is one representative trial. $n>20$ cells/strain/experiment for 2 independent trials. $p$ value $<0.0001$ (Mantel-Cox test). Right: Scatter plot displaying the total number of divisions generated by the mother cells in each genotype. 
Figure 4. BUD1 and MFB1 function in the same pathway for mitochondrial distribution and quality control and RLS.

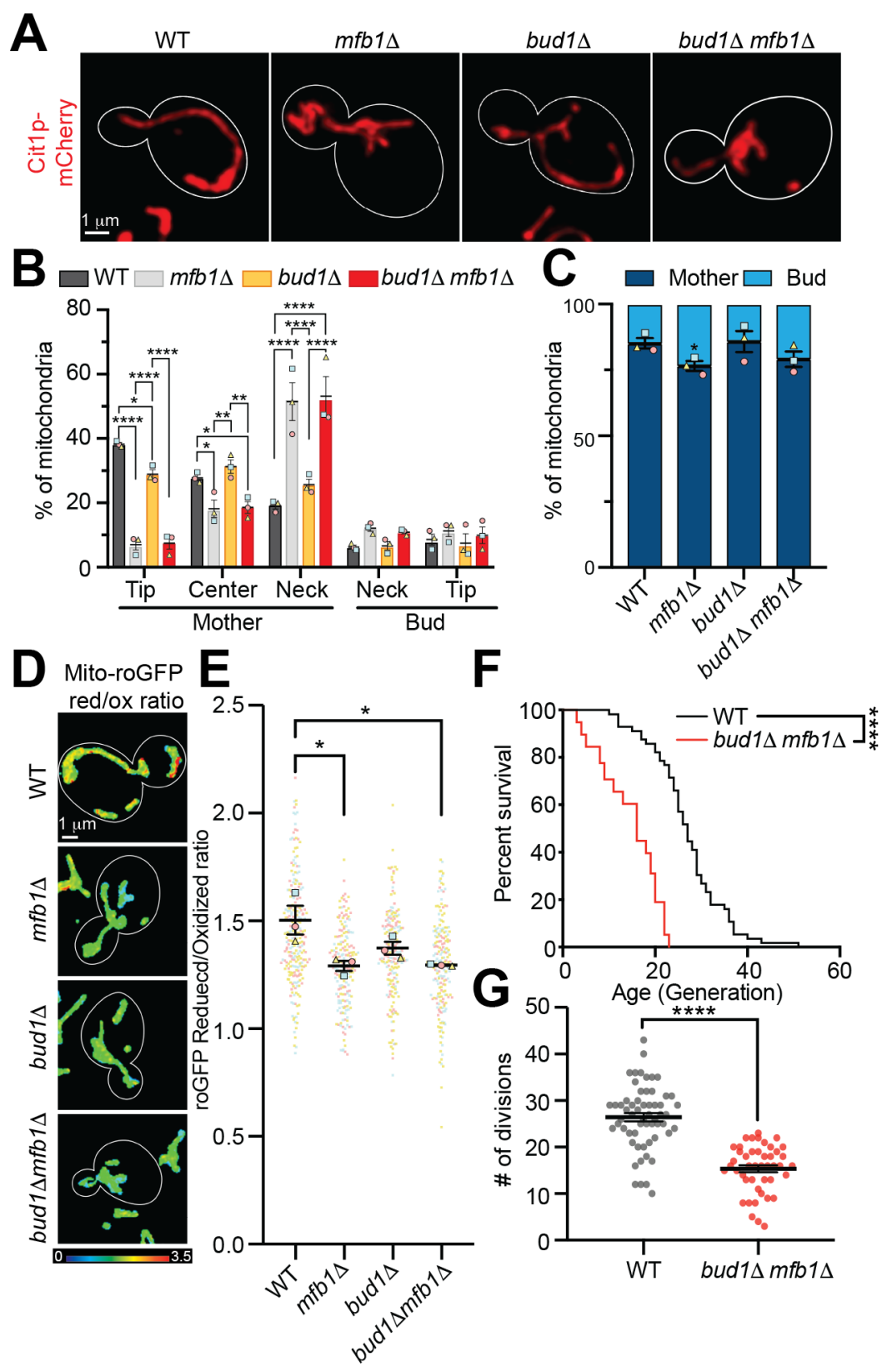

Figure 4. BUD1 and MFB1 function in the same pathway for mitochondrial distribution and quality control and RLS. (A) Maximum projections of mitochondria visualized using Cit1p-mCherry in mid-log phase WT, $m f b 1 \Delta$, bud1 $\Delta$, and bud1 $\Delta$ mfb1 $1 \Delta$ cells. Cell outlines: white. Scale bars: $1 \mu \mathrm{m} . \mathrm{n}>100$ cells/strain/trial. (B, C) Quantification of the mitochondrial distribution of (A). ROls are defined in Fig. 1B. $>100$ cells/strain/trial. The means of 3 independent trials are shown in different shaped and colored symbols for each trial. (D) Maximum projections of ratiometric images of reduced/oxidized integrated mito-roGFP1 in mid-log phase WT, $m f b 1 \Delta$, bud1 1 , and bud1 $\Delta \mathrm{mfb} 1 \Delta$ cells. Colors reflect the intensity of 
the ratio of reduced-to-oxidized mito-roGFP1 (scale at the bottom right.) Cell outlines: white. $n>181$ cells/strain/trial. (E) Quantification of reduced/oxidized mito-roGFP1 of mitochondria in mother cells of indicated genotypes from panel (D). The mean of 3 independent trials, with differently shaped and colored symbols for each trial. Mean of the ratio of reduced/oxidized mito-roGFP1: $1.505 \pm 0.0669$ (WT), $1.293 \pm$

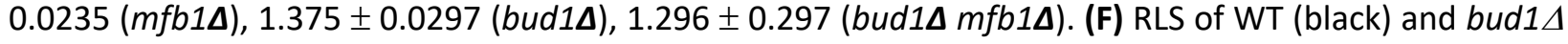
$m f b 1 \Delta$ (red) cells was measured as for Fig. 3F. $p<0.0001$ (Mantel-Cox test). Data shown is one representative trial. $n>20$ cells/strain/trail for 2 independent experiments. (G) Scatter plot displaying the total number of divisions generated by the mother cells in each genotype in (F). 
Supplemental Figure 1. Isolation of cells of defined replicative age using a Miniature Chemostat Aging Device.
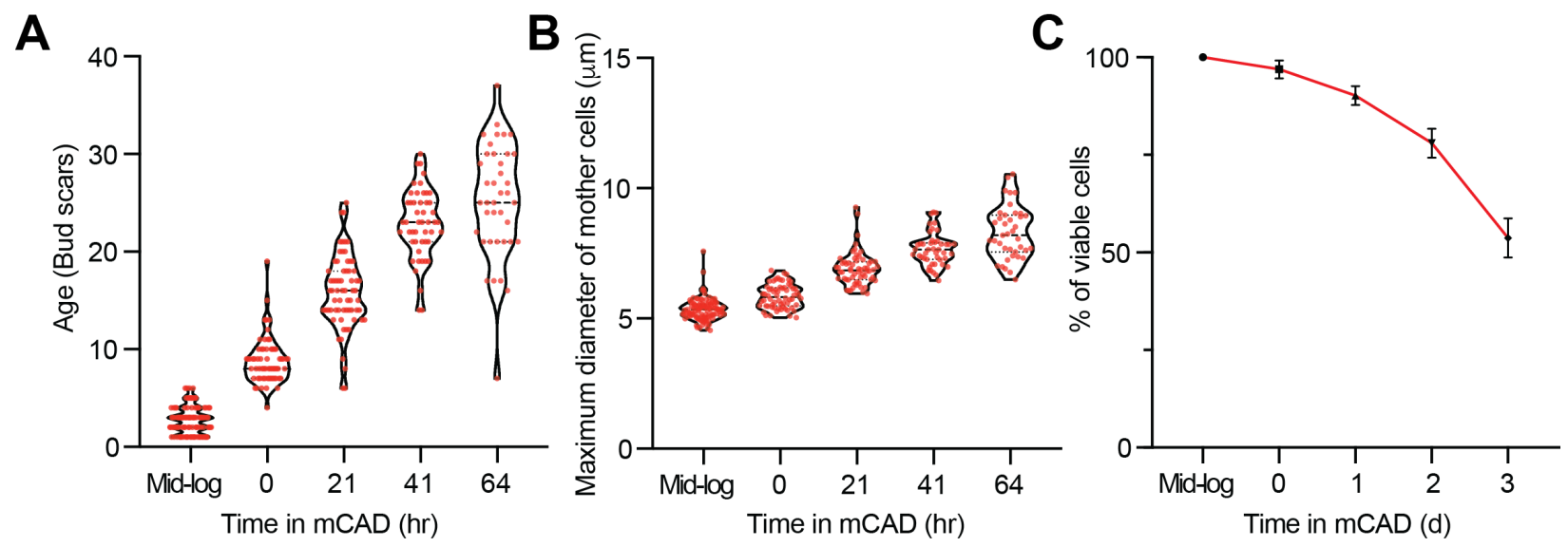

Supplemental Figure 1. Isolation of cells of defined replicative age using the Miniature Chemostat Aging Device. (A) Age of mother cells during a 64-hr mCAD time course. Age was determined by counting bud scars stained by AlexaFluor-WGA. Average age of mother cells at different time points: $2.75 \pm 0.136$ (mid$\log ), 8.79 \pm 0.294(0 \mathrm{hr}), 15.83 \pm 0.467(21 \mathrm{hr}), 22.84 \pm 0.505(49 \mathrm{hr}), 25.26 \pm 0.937$ ( $64 \mathrm{hr}) . \mathrm{n}>40$ for each time point. (B) Diameter of mother cells during mCAD time course. Average diameter of mother cells at different time points: $5.34 \pm 0.041$ (mid-log), $5.85 \pm 0.057$ (0 hr), $6.90 \pm 0.082$ (21 hr), $7.66 \pm 0.0942$ (45 $\mathrm{hr}$ ), $8.3 \pm 0.162$ (64 hr). $\mathrm{n}>40$ for each time point. (C) Average percentage viability of mother cells from 3 independent $\mathrm{mCAD}$ experiments. Average percentage of viable cells: $96.93 \pm 2.313$ ( $0 \mathrm{~d}$ ), $90.24 \pm 2.415$ (1 d), $78 \pm 3.675$ ( 2 d), $53.7 \pm 4.975$ ( 3 d). $n=3$ independent trials. 
Supplemental Figure 2. Mfb1p co-localizes with mitochondria during the entire lifespan in yeast.

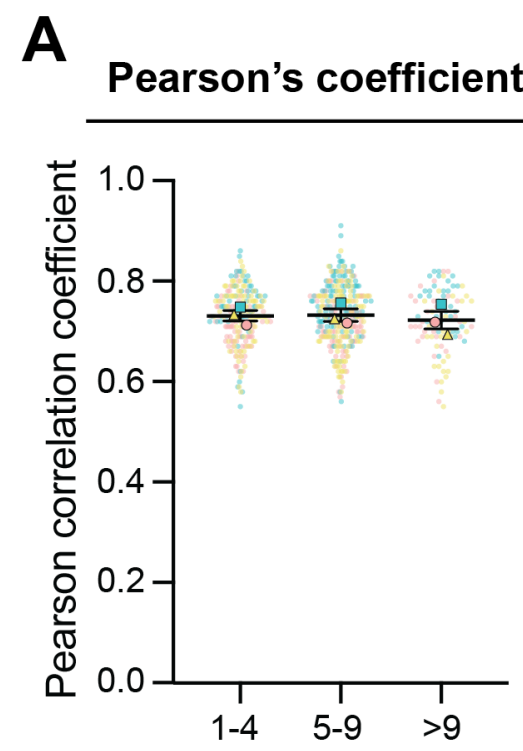

\section{B}

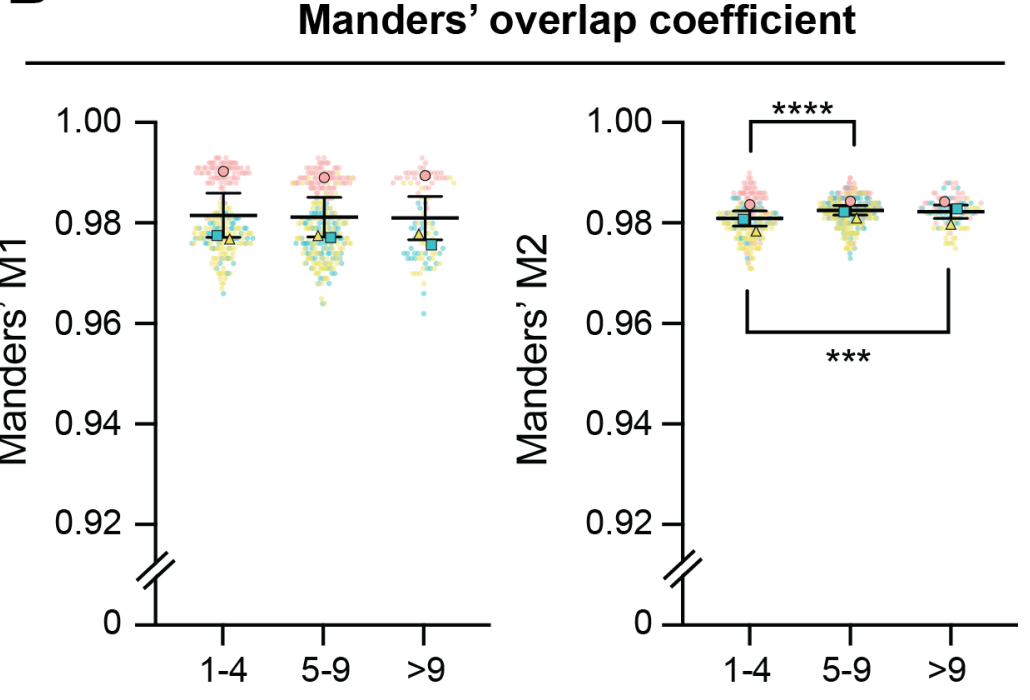

Age (Generation)

Supplemental Figure 2. Mfb1p co-localizes with mitochondria during the entire lifespan in yeast. ( $A$ and B) Images were subjected to background subtraction before automatic thresholding by the Coloc2 plugin using the bi-sectional method in Fiji. Co-localization assays were performed by comparing signal correlation between the Mfb1p-GFPEnvy and Cit1p-mCherry channels. The means of 3 independent trials are shown in different shaped and colored symbols for each trial. (A) Pearson's correlation coefficients of co-localization as a function of replicative age. The Pearson correlation coefficient ranges from - 1 (perfect anti-correlation) to +1 (perfect correlation). Average Pearson's correlation coefficients: $0.733 \pm 0.004$ (14 generations), $0.73 \pm 0.004$ (5-9 generations), $0.723 \pm 0.007$ ( $>9$ generations), $n>70$ for each age group. There are no significant differences between age groups using one-way ANOVA with Tukey's multiple comparisons test. (B) Manders' correlation coefficient for colocalization as a function of replicative age. $\mathrm{M} 1$ is defined as Mfb1p co-occurrence with mitochondria. Average Manders' M1 coefficients as a function of age: $0.976 \pm 0.0003$ (1-4 generations), $0.977 \pm 0.0003$ (5-9 generations), $0.977 \pm 0.0007$ (>9 generations). $n>60$ for each age group. $\mathrm{M} 2$ is defined as mitochondria co-occurrence with Mfb1p. Average Manders' M2 coefficient as a function of age: $0.98 \pm 0.0003$ (1-4 generations), $0.982 \pm 0.0002$ (5-9 generations), $0.982 \pm 0.0003$ ( $>9$ generations). 


\section{Supplemental Figure 3. Deletion of MFB1 has no effect on polarized bud site selection.}
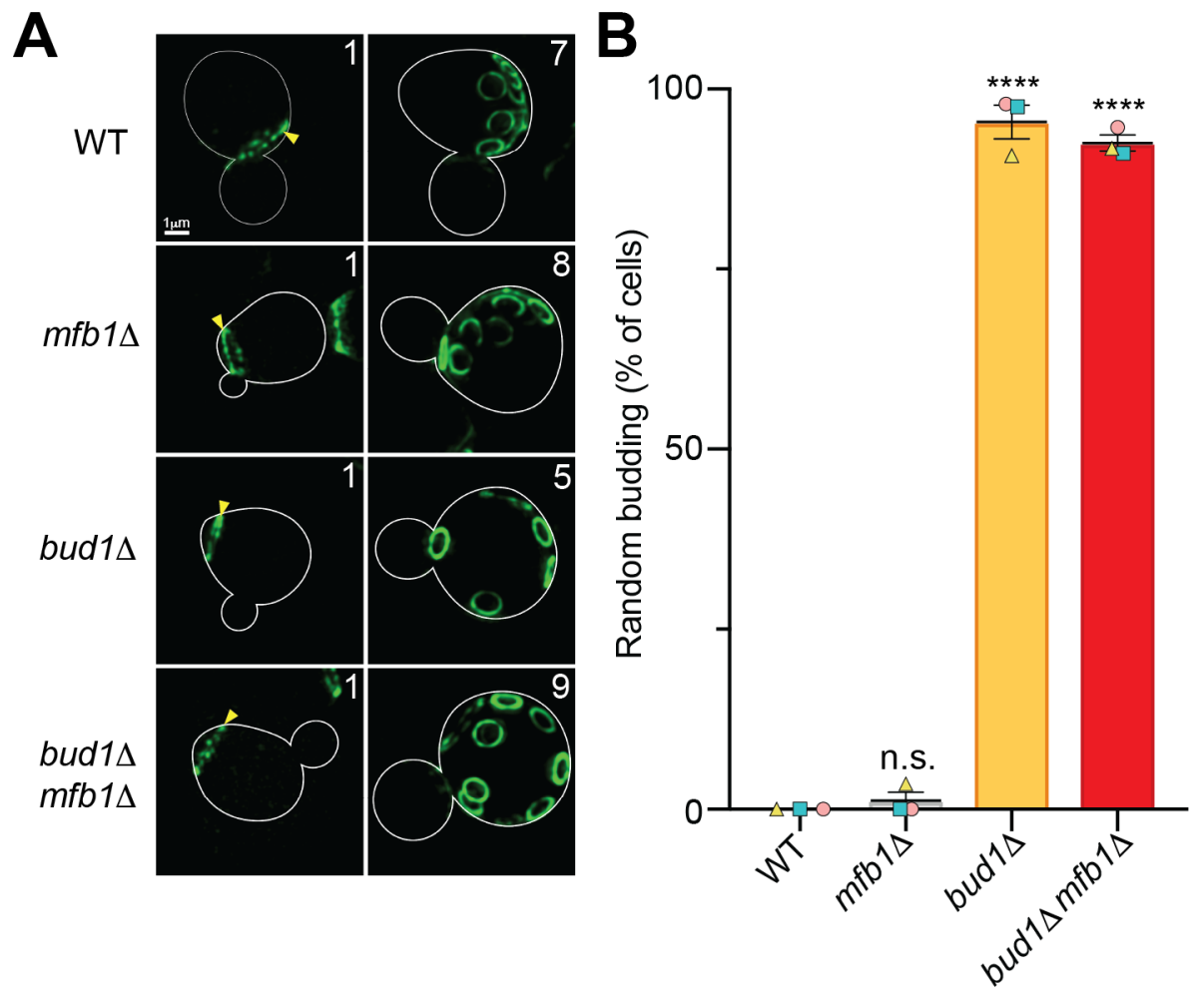

Supplemental Figure 3. Deletion of MFB1 has no effect on polarized bud site selection. (A) Maximum projection images of Alexa488-WGA stained birth and bud scars of WT, $m f b 1 \Delta$, bud1 $\Delta$, and bud1 $\Delta \mathrm{mfb} 1 \Delta$ cells. Yellow arrowheads point to the birth scar of each cell. (B) Percentage of cells undergone polarized budding. The means of 3 independent trials are shown in different shaped and colored symbols for each trial. ( $p<0.0001$, one-way ANOVA with Tukey's multiple comparisons test.) 
Supplemental Figure 4. Mfb1p co-localizes with mitochondria in bud1A.

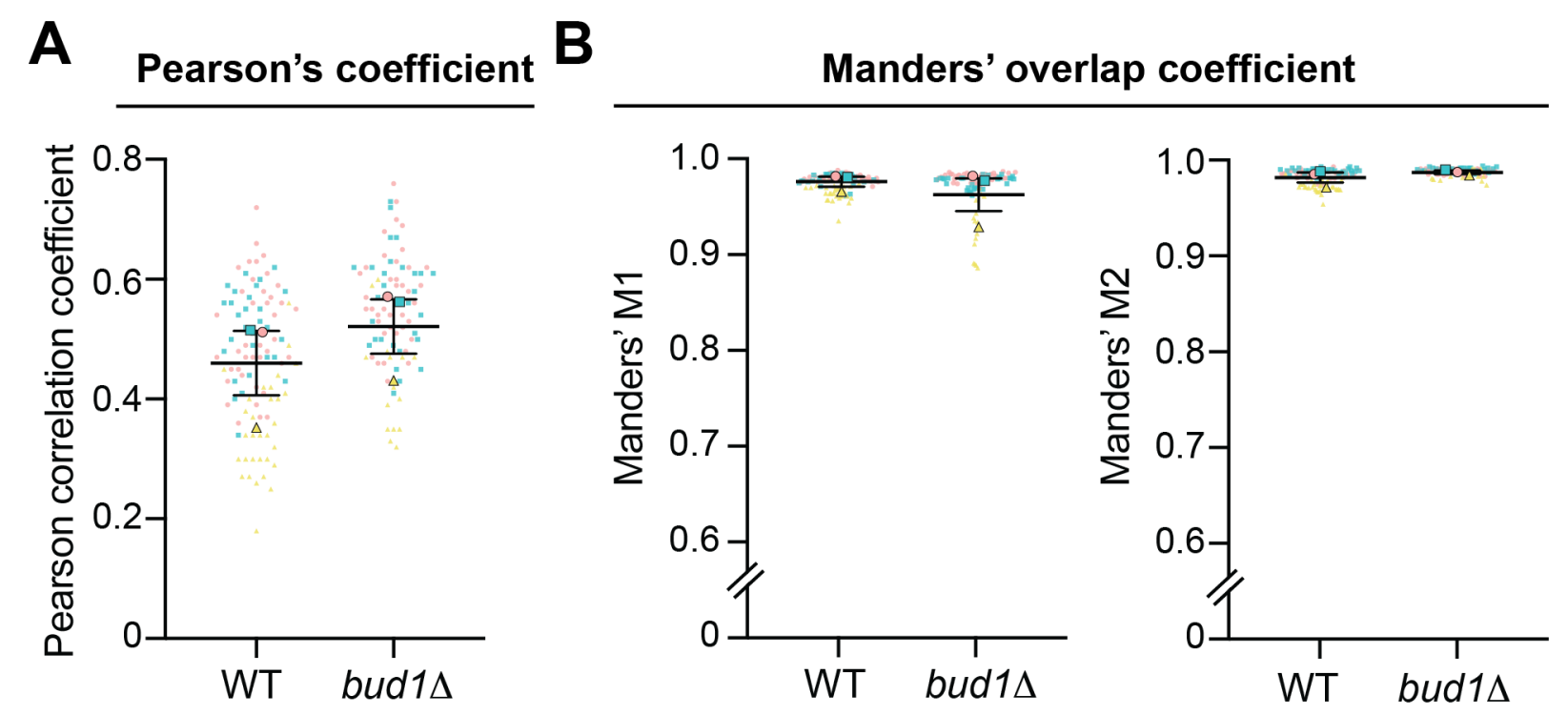

Supplemental Figure 4. Mfb1p co-localizes with mitochondria in bud1 $\Delta$ cells. (A and B) Images were preprocessed and analyzed as described in Supplemental Figure 2. The means of 3 independent trials are shown in different shaped and colored symbols for each trial. (A) Pearson's correlation coefficients of colocalization in WT and bud1 $\Delta$ cells. The Pearson correlation coefficient ranges from -1 (perfect anticorrelation) to +1 (perfect correlation). Average Pearson's correlation coefficients for WT $=0.46 \pm 0.0536$, bud1 $\Delta=0.521 \pm 0.0454, \mathrm{n}>30$ for each genotype. There are no significant differences in between each age group using Mann-Whitney test $(p=0.4)$. (B) Manders' correlation coefficient for colocalization as a function of replicative age. $\mathrm{M} 1$ is defined as Mfb1p co-occurrence with mitochondria. Average Manders' M1 coefficients in WT and bud1 $\Delta$ cells: $0.975 \pm 0.0051$ (WT), $0.961 \pm 0.0171$ (bud1A). There are no significant differences between age groups by the Mann-Whitney test ( $p>0.9999)$. $n>30$ for each genotype. $\mathrm{M} 2$ is defined as mitochondria co-occurrence with Mfb1p. Average Manders' $\mathrm{M} 2$ coefficient in WT and bud1 $\Delta$ cells: $0.982 \pm 0.0052$ (WT), $0.9875 \pm 0.0018$ (bud1 $\Delta$ ). There are no significant differences in between each age group using Mann-Whitney test $(p=0.7) . \mathrm{n}>30$ for each genotype. 


\section{STAR Methods}

\section{Yeast Growth Conditions}

All S. cerevisiae strains used in this study were generated in BY4741 (MATa his3 $\Delta 0$, leu2 $\Delta 0$, met15 $\triangle 0$ and ura3 $\triangle 0$ ) background from Open Biosystems (Huntsville, $\mathrm{AL}$ ). The maintenance and manipulation of yeast cells were conducted as previously described (Sherman, 2002). Yeast cells were propagated in YPD medium [1\% (w/v) yeast extract (BD, Franklin Lakes, NJ), 2\% (w/v) Bacto-peptone (BD, Franklin Lakes, NJ), and 2\% (w/v) dextrose (Sigma-Aldrich, St. Louis, MO)] at $30{ }^{\circ} \mathrm{C}$ with vigorous shaking at $180-200$ rotations per minutes (RPM). All experiments were carried out with liquid cultures grown to the mid-logarithmic phase (O.D.600 0.1-0.3). For aging experiments using the mCAD device, yeast cells were grown in Synthetic Complete (SC) media. For imaging experiments, all strains were washed once in SC medium [0.67\% (w/v) Yeast nitrogen base without amino acids and with ammonium sulfate, amino acid mix, 2\% (w/v) glucose] to reduce auto-fluorescence from YPD medium. A list of yeast strains used in this study is in Supplementary Table 1.

\section{Yeast Strain Construction}

Knockout or tagged strains were generated essentially as described (Gardner and Jaspersen, 2014). Knockout strains were generated by using homologous recombination to replace the target genes with LEU2 selectable marker cassettes. The marker cassette was PCRamplified from pOM13 plasmid (Gauss et al., 2005) with $40 \mathrm{bp}$ of flanking homology upstream and downstream of the target gene. PCR reactions were performed using the KAPA HiFi PCR kit. The PCR fragments were transformed into yeast cells by the lithium acetate method described in (Gietz and Woods, 2002). In brief, yeast cells were grown to the mid-logarithmic phase, and about $2 \times 10^{8}$ cells were aliquoted and harvested at $3,000 \times \mathrm{g}$ for 1 minute. Cells were washed once with $0.1 \mathrm{M}$ of lithium acetate, and mixed with a transformation mixture consisting of $33.33 \%$ of PEG3350, $0.1 \mathrm{M}$ lithium acetate, $0.1 \mathrm{mg}$ of boiled salmon sperm carrier DNA, and $50 \mu \mathrm{L}$ of unpurified PCR product. The transformation mixture was incubated at $30^{\circ} \mathrm{C}$ for 30 minutes, and subsequently incubated at $42{ }^{\circ} \mathrm{C}$ for 45 minutes. Transformants were selected on agar plates containing SC medium without leucine (SC-Leu) for 2 days. Successful transformants were confirmed by sequencing the inserted region. 
To visualize Mfb1p, a bright GFP variant, GFPEnvy, was fused to the C-terminal of Mfb1p by genetic manipulation. All GFPEnvy tagged strains were generated by using the lithium acetate method described above to insert a PCR product containing the GFPEnvy gene with the SpHis5 selectable marker after the coding region of the gene of interest. The primer sets were designed to amplify PCR fragments with 40 bp of flanking homology upstream and downstream of the stop codon of the target sequence. The backbone of the PCR product was amplified from the pFA6alink-GFPEnvy-SpHis5 plasmid (Addgene plasmid \# 60782). The PCR cassette was transformed into yeast cells and selected based on the lithium acetate transformation method described above. Transformants were selected on SC medium without histidine (SC-His) plates.

The visualization of mitochondria was achieved by C-terminally fusing mCherry to a=the mitochondrial matrix protein Cit1p. The mCherry fluorophore and the $h p h M X 4$ selectable marker was amplified from pCY3090-02 with 40 bp of flanking homology. The PCR cassette was transformed into yeast cells and selected based on the lithium acetate transformation method described above. Transformants were selected on YPD plates containing $200 \mu \mathrm{g} / \mathrm{ml}$ hygromycin B (Sigma-Aldrich, St. Louis, MO).

To perform ratiometric quantification of mitochondrial redox state, endogenously expressed GDPp-mito-roGFP1 followed by the KanMX4 selectable marker was integrated into the HO locus. The PCR cassette was transformed into yeast cells and selected based on the lithium acetate transformation method described above. Transformants were selected on YPD plates containing $200 \mu \mathrm{g} / \mathrm{ml}$ Geneticin (Sigma-Aldrich, St. Louis, MO).

The plasmids and primers used in strain construction are listed in Supplementary Tables 2 and 3.

\section{Microscopy}

Fluorescence microscopy was performed with one of the following imaging systems: (1) a Zeiss Axioskop 2 Plus upright fluorescence microscope with a 100x/1.4 Numerical Aperture (NA) Zeiss Plan-Apochromat objective lens (Carl Zeiss Inc., Thornwood, NY), Light-Emitting Diode (LED) module (CoolLED pE-4000, Andover, UK) and an Orca ER cooled charge-coupled device (CCD) camera (Hamamatsu Photonics, Hamamatsu City, Japan), and (2) a Zeiss AxioObserver.Z1 inverted fluorescence microscope with a 100x/1.3 oil EC Plan-Neofluar objective lens, a metal-halide lamp and an LED Colibri system (Carl Zeiss Inc., Thornwood, NY), 
and Orca ER cooled CCD. The first system was controlled by NIS Elements 4.60 Lambda software (Nikon, Melville, NY), and the second system was controlled by Zen Blue (Carl Zeiss Inc., Thornwood, NY). Details about the imaging conditions are given within each experimental section below.

\section{Visualization of Bud Scars}

To determine the age of yeast cells, bud scars were visualized by staining with Calcofluor White M2R (Millipore Sigma, Burlington, MA) or WGA conjugated to Alexa Fluor 488, 594 or 647 (Thermo Fisher Scientific, Waltham, MA). For calcofluor staining, $25 \mu \mathrm{M}$ Calcofluor White M2R was incubated with yeast cells for 5 minutes, followed by 3 washes with SC media. Calcofluor-stained cells were imaged using a standard DAPI filter set (Chroma/ Zeiss filter set 49; excitation G365, dichroic FT 395, emission 445/50). For WGA staining, $1 \mu \mathrm{g} / \mathrm{mL}$ WGA conjugated to AlexaFluor was added to a yeast cell culture and incubated for 15 minutes, followed by 3 washes with SC media. AlexaFluor 488 was excited by a $470 \mathrm{~nm}$ LED and AlexaFluor 594 was excited by $561 \mathrm{~nm}$ LED, and emission was collected with a dual eGFP/mCherry cube (\#59222, Chroma, Bellows Falls, VT), or a far-red filter set (Zeiss filter set $50 \mathrm{HE}$; excitation 640/30, emission 690/50).

\section{Enrichment of Aged Cells}

Aged cell enrichment by binding to magnetic beads was performed as described in (Lindstrom and Gottschling, 2009; Sinclair et al., 1997; Smeal et al., 1996) with modifications. Cultures were grown overnight in YPD at $30^{\circ} \mathrm{C}$ to an $\mathrm{OD}_{600}<0.2$ as described above. $10^{8}$ total cells (roughly $10 \mathrm{OD}_{600}$ ) of cells were harvested by centrifuging at $1500 \times \mathrm{g}$ using a Sorvall ST-16 tabletop centrifuge for 5 minutes. Cells were washed with $10 \mathrm{~mL}$ of ice-cold 1x phosphate-buffered saline (PBS) [137 mM sodium chloride, $2.7 \mathrm{mM}$ potassium chloride, $10.14 \mathrm{mM}$ sodium phosphate dibasic, and $1.77 \mathrm{mM}$ potassium phosphate monobasic, and adjusted to $\mathrm{pH}$ 8.] Cells were labeled with $10 \mathrm{mM}$ of EZ Link ${ }^{\mathrm{TM}}$ Sulfo-NHS-LC-LC-biotin (\#21338, Thermo Fisher Scientific, Waltham, MA) dissolved in $1 \times$ PBS for 30 minutes with gentle rotation at room temperature. The excessive biotin was quenched by washing cells three times with 1x PBS containing $100 \mathrm{mM}$ glycine. Cells were resuspended in $1 \mathrm{~mL}$ of YPD and used to inoculate $500 \mathrm{~mL}$ of YPD media at a density of $2 \times 10^{5}$ cells $/ \mathrm{mL}$ in a $2-\mathrm{L}$ Erlenmeyer flask. Biotinylated cells were propagated at $30^{\circ} \mathrm{C}$ for $8 \mathrm{hrs}$. The $\mathrm{OD}_{600}$ of the culture was monitored and was not allowed to exceed 0.8 . Cells were fixed by adding $20 \%$ of formaldehyde to a final concentration of $3.7 \%$ and incubated at $30{ }^{\circ} \mathrm{C}$ with vigorous 
shaking for 50 minutes. Fixed cells were harvested by centrifuging at $3000 \times \mathrm{g}$ for 5 minutes, and washed with $10 \mathrm{~mL}$ of $1 \times$ PBS for 3 times. Cell density was measured and adjusted to $90 \mathrm{OD}_{600}$ per $\mathrm{mL}$, and cells were divided into $500-\mu \mathrm{L}$ aliquots in $1.5 \mathrm{ml}$ Eppendorf tubes. Miltenyi $\mu \mathrm{MACs}$ Streptavidin MicroBeads (\#130-048-101, Miltenyi Biotec Inc., Auburn, CA) were added (20 $\mu \mathrm{L}$ beads $/ 45 \mathrm{OD}_{600}$ cells) and rotated at room temperature for $30 \mathrm{~min}$. Cells were washed twice with $1 \mathrm{~mL}$ of $1 \mathrm{x}$ PBS and then resuspended in $1 \mathrm{~mL}$ of $1 \mathrm{x}$ PBS. The cell suspension was sorted by MACS LS separation columns (\#130-042-401, Miltenyi Biotec Inc., Auburn, CA). The separation columns were washed with $2 \mathrm{~mL}$ of $1 \times$ PBS and eluted with $2 \mathrm{~mL}$ of YPD by firmly pushing the plunger into the column. Enriched mother cells were stained with Calcofluor White as described above.

Enrichment of aged cells in the miniature-Chemostat Aging Device and assessment of bud site selection

To determine the budding polarity in cells of different ages, aged cells were enriched in a miniature-Chemostat Aging Device (mCAD) and stained sequentially with WGA conjugated with AlexaFluor 488 and AlexaFluor 594. The assembly of the mCAD is described in (Hendrickson et al., 2018). In brief, cells were grown overnight to mid-log phase $\left(O D_{600}<0.2\right) .4 O_{600}-m L$ of cells were harvested by centrifuging at $1500 \mathrm{xg}$ in a Sorvall ST-16 tabletop centrifuge for 5 minutes, and washed twice with $5 \mathrm{~mL}$ of $1 \times$ PBS with $0.25 \%$ PEG3350. The cell pellet was resuspended in $0.5 \mathrm{~mL}$ of $1 x$ PBS and then combined with $2 \mathrm{mg}$ of EZ Link ${ }^{\mathrm{TM}}$ Sulfo-NHS-LC-LC-Biotin dissolved in $0.5 \mathrm{~mL}$ of $1 \mathrm{x}$ PBS. The biotin labeling reaction was carried out at room temperature for 30 minutes with gentle rotation. After the reaction, cells were washed twice with 1x PBS with $0.25 \%$ PEG3350 and then resuspended in $500 \mathrm{~mL} \mathrm{SC}$ media in a $2 \mathrm{~L}$ Erlenmeyer flask. The biotin-labeled cells were grown at $30^{\circ} \mathrm{C}$ with shaking at 190-200 RPM for 8 hours. The OD 600 of the culture was monitored and was not allowed to exceed 0.3.

Labeled cells were counted using a hemocytometer. $0.9 \mu \mathrm{L}$ of magnetic beads was used per 1 million labeled cells. Before the beading reaction, the Dynabeads MyOne Streptavidin C1 beads (\#65001, Thermo Fisher Scientific) were equilibrated to room temperature and washed twice with $1 \mathrm{~mL}$ of SC media, and then resuspended in $20 \mathrm{~mL}$ of SC.

The post-biotinylated cell culture was harvested by centrifugation at $1500 \times \mathrm{g}$ for 5 minutes in a $50 \mathrm{~mL}$ conical-bottom tube, and the pellet was resuspended in $20 \mathrm{~mL}$ of $\mathrm{SC}$. The concentrated cells were mixed with washed magnetic beads and rotated for 15 minutes at room temperature. 
The mother cells attached to magnetic beads were separated by ring magnets for 5 minutes. The supernatant was carefully removed and saved as young cells. The beaded mother cells were washed twice with $40 \mathrm{~mL}$ of $\mathrm{SC}$, and then resuspended in $1 \mathrm{~mL}$ of SC media for $\mathrm{mCAD}$ loading.

For cell loading onto the mCAD, the vessel of the mCAD was removed from the magnets, and the air pump was set to the lowest airflow or none, and the effluent port was pulled above the media level or blocked by a tubing clamp. Beaded mother cells were transferred to a $1 \mathrm{~mL}$ Luer lock syringe and then loaded into the mCAD vessel by the Luer needle entry port. The loaded vessel was swirled to mix the cells, and placed on magnets to allow beaded mother cells to bind for 10 to 15 minutes. The media peristaltic pump ( $25 \mathrm{~mL}$ per hour) and air pump ( 0.8-1 psi) were started after binding of beaded mother cells.

During mother cell harvesting, the media pump was off, and the air pump was set to the lowest setting. The effluent port was pulled up or blocked by a tubing clamp. The vessel was removed from the magnet and swirled to mix the cells. Mother cells were collected by using a Luer-lock syringe drawing from the loading port of the mCAD. The harvested cells were washed 4 times on magnets before the next procedure.

To distinguish the budding pattern in aged cells, cells were stained with WGA conjugated with 2 different AlexaFluor for visualizing the newest two bud scars on the cell surface. The staining process is described in the "Visualization of Bud Scars" section. The mother cells were stained with WGA-Alexa488 for 15 minutes, washed 3 times, and diluted to $\mathrm{OD}_{600}<0.2$ in $5 \mathrm{~mL}$ of SC media and grown for 90 minutes at $30^{\circ} \mathrm{C}$. Cells were then harvested and stained with WGA-Alexa594 and washed as above. Washed cells were resuspended in $\sim 2 \mu \mathrm{L}$ of SC and mounted on microscope slides (\#3050, Thermo Fisher Scientific). Mounted cells were visualized on the microscope system 1 described above.

\section{Analysis of Mitochondrial and Mfb1p Distribution}

Analysis of mitochondrial distribution was performed as previously described (Pernice et al., 2016). In brief, yeast cells expressing endogenously tagged Cit1p-mCherry were imaged on System 1 or 2 using (1) a standard RFP filter set (Chroma) or (2) a Zeiss filter set $43 \mathrm{HE}$, excitation FT 570, dichroic FT 570, emission 605/70. Cells were imaged through the entire cell depth (6 $\mu \mathrm{m}$ total, with $0.3 \mu \mathrm{m}$ z-steps), using $1 \times 1$ binning, $300 \mathrm{~ms}$ exposure with $561 \mathrm{~nm}$ LED with $55 \%$ power. For Mfb1p distribution, selected yeast strains expressing endogenously tagged Mfb1p- 
GFP or Mfb1p-GFPEnvy were imaged on System 1 or 2, with excitation by a $470 \mathrm{~nm}$ LED and emission collected through either (1) a dual eGFP/mCherry cube (\#59222, Chroma), or (2) a Zeiss filter set $38 \mathrm{HE}$, excitation 470/40, dichroic FT 495, emission 525/50, respectively. Acquired widefield images were deconvolved by an iterative restoration algorithm in Volocity (Quorum Technologies, Ontario, Canada) with a limit of 60 iterations. The relative distribution of mitochondrial mass was quantified by thresholding the mitochondrial voxels from 3D reconstructed microscopy images and calculating volume in 5 different regions (mother tip, mother center, mother neck, bud neck and bud tip, as defined in Fig. 2B). The mother and bud diameters were measured along the longest axis of the cell based on the transmitted-light images. To quantify cells at similar cell cycle stages, cells were omitted if the bud-to-mother ratio was smaller than 0.2 or larger than 0.6 .

\section{Analysis of Co-localization of Mfb1p and Mitochondria}

Co-localization between Mfb1p-GFPEnvy and mitochondria (Cit1p-mCherry) was calculated by using the Coloc2 plug-in in Fiij. Pearson's and Manders' coefficients were calculated to assess the correlation and co-occurrence, respectively, of the signals. The background of microscopic images was determined as the mean of a cell-free region near the cell of interest, and was subtracted from the image. Coloc2 was called with bisection threshold regression with a Region of Interest (ROI) flanking the cell. Coefficients and 2D intensity plots were calculated and visually inspected. Negative controls were performed by comparing a randomized channel with another channel.

\section{Analysis of Mitochondrial Redox State}

Analysis of mitochondrial redox state was conducted according to (Vevea et al., 2013)with modifications. The redox biosensor roGFP1 with mitochondrial targeting sequence from ATP9 was introduced into strains of interest by integration into the $\mathrm{HO}$ locus. Cells in mid-log phase were imaged on System 1 by excitation wavelength switching between $365 \mathrm{~nm}$ and $470 \mathrm{~nm}$, and collecting emission through a modified GFP filter (Zeiss filter $46 \mathrm{HE}$ without excitation filter, dichroic FT 515, emission 535/30). For the oxidized form of roGFP, a 300-ms exposure with 50\% LED power was used, and for the reduced form a 200-ms exposure with $20 \%$ LED power. The wide-field images were deconvolved as described above. The background was calculated by selecting a background ROI and subtracted from the image by thresholding in the Ratio function in Volocity. The reduced-to-oxidized mito-roGFP ratio was calculated by dividing the voxel 
intensity of reduced $(\lambda e x=470 \mathrm{~nm}, \lambda e m=525 \mathrm{~nm})$ over oxidized $(\lambda e x=365 \mathrm{~nm}, \lambda e m=525 \mathrm{~nm})$ channel. The resulting ratio channel was measured with exclusion of zero values. The mother and bud diameters were measured as described above, and the same cell-size criteria were used to exclude cells in different cell cycle stages.

\section{Analysis of Replicative Lifespan}

Replicative lifespan (RLS) measurements were performed as described previously (Erjavec et al., 2008), without alpha-factor synchronization. Briefly, frozen glycerol stocks of select strains (stored at $-80^{\circ} \mathrm{C}$ ) were streaked out on YPD plates and grown for 2 days. Single colonies were grown overnight in liquid YPD at $30^{\circ} \mathrm{C}$, diluted and grown to exponential phase for $4 \mathrm{hrs}$ in YPD at $30^{\circ} \mathrm{C} .2 \mu \mathrm{l}$ of the cell suspension was streaked onto a YPD plate and small-budded cells were isolated and arranged in a matrix using a micromanipulator mounted onto a dissecting microscope (Zeiss, Thornwood, NY). Upon completion of budding, mother cells were discarded; the time and number of divisions of the corresponding daughter cells were recorded until all replication ceased.

\section{Quantification and Statistical Analysis}

All quantifications were subjected to normal distribution analysis with the D'Agostino and Pearson normality test. Statistical $p$ values for two-group comparison were conducted by a twotailed Student's t test for parametric distributions and a Mann-Whitney test for non-parametric results. For more than two-group comparisons, $\mathrm{p}$ values were calculated by a one-way ANOVA with Dunnett's or Sidak's test for parametric distributions and a Kruskal-Wallis test with Dunn's post hoc test for non-parametric distributions. Results were recorded and sorted in Microsoft Excel and the statistical analyses were done in GraphPad Prism8 (GraphPad Software, San Diego, CA). Bar graphs and scatter graphs show the mean and standard error of the mean (SEM). For all statistical tests, $p$ values are denoted as followed: ${ }^{* \star *} p<0.0001 ;{ }^{* * *} p<0.001 ;{ }^{* *} p<0.01$; $\mathrm{p}<0.05$. 


\section{Strains used in this study:}

\begin{tabular}{|c|c|c|}
\hline Strains & Genotype & Reference \\
\hline BY4741 & MATa his $3 \Delta 1$ leu $2 \Delta 0$ met $15 \Delta 0$ ura $\Delta \Delta 0$ & Open Biosystems \\
\hline JYY107 & $\begin{array}{l}\text { MATa his3 } 11 \text { leu2 } \Delta 0 \text { met } 15 \Delta 0 \text { ura3 } \Delta 0 \text { Mfb1p- } \\
\text { GFPEnvy::SpHis5 Cit1p-mCherry::hphMX }\end{array}$ & This study \\
\hline JYY104 & 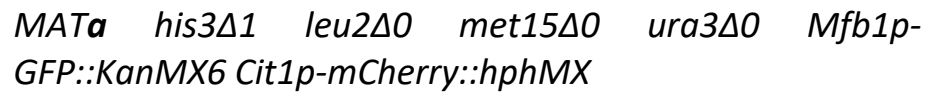 & (Pernice et al., 2016) \\
\hline JYY106 & 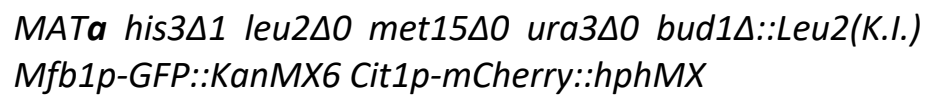 & This study \\
\hline JYY134 & $\begin{array}{l}\text { MATa his } 3 \Delta 1 \text { leu2 } \triangle 0 \text { met15 } \Delta 0 \text { ura3 } \Delta 0 \text { ho } \Delta p G P D-m i t o- \\
\text { roGFP::KanMX6 }\end{array}$ & This study \\
\hline JYY137 & 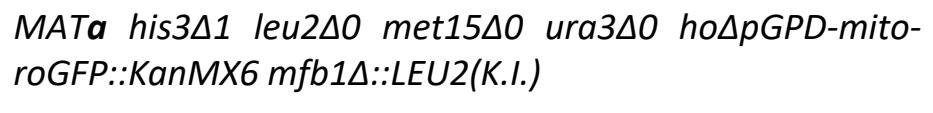 & This study \\
\hline JYY143 & $\begin{array}{l}\text { MATa his } 3 \Delta 1 \text { leu } 2 \Delta 0 \text { met15 } \triangle 0 \text { ura3 } \triangle 0 \text { ho } \Delta p G P D-\text { mito- } \\
\text { roGFP::KanMX6 bud } 1 \Delta:: \text { loxP }\end{array}$ & This study \\
\hline JYY149 & 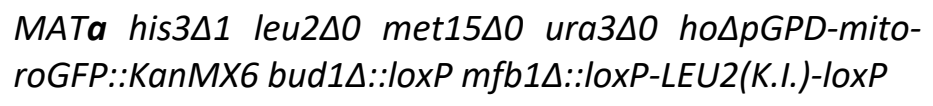 & This study \\
\hline JYY066 & 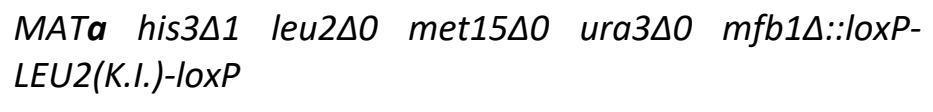 & (Pernice et al., 2016) \\
\hline JYY065 & 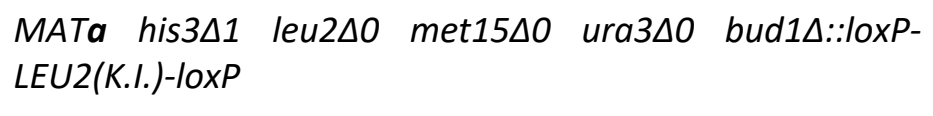 & This study \\
\hline JYY072 & 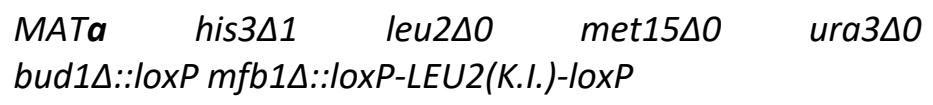 & This study \\
\hline JYY063 & $\begin{array}{l}\text { MATa his } 3 \Delta 1 \text { leu2 } \Delta 0 \text { met15 } \Delta 0 \text { ura3 } \Delta 0 \text { Cit1p- } \\
\text { mCherry::hphMX }\end{array}$ & (Pernice et al., 2016) \\
\hline JYY052 & 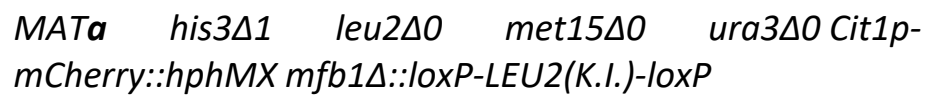 & This study \\
\hline
\end{tabular}




\begin{tabular}{|c|c|c|}
\hline JYY053 & $\begin{array}{l}\text { MATa his } 3 \Delta 1 \text { leu2 } \Delta 0 \text { met15 } \triangle 0 \text { ura3 } \Delta 0 \text { Cit1p- } \\
\text { mCherry::hphMX bud1 }:: \text { loxP-LEU2(K.I.)-loxP }\end{array}$ & This study \\
\hline JYY055 & 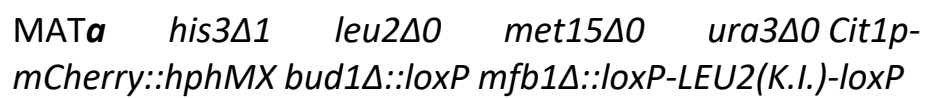 & This study \\
\hline
\end{tabular}

\section{Plasmids used in this study:}

\begin{tabular}{lll}
\hline Plasmid & Name & Source \\
\hline JYE018 & pFA6a-GFPEnvy-SpHis5 & $\begin{array}{l}\text { Linda Huang (Addgene, 60,782) (Slubowski et al., } \\
2015)\end{array}$ \\
\hline JYE019 & pCY3090-02 & Anne Robinson (Addgene, 36,231) \\
\hline & pFA6a-GFP-KanMX6 & Jurg Bahler and John Pringle (Addgene, 39,292) \\
\hline JYE057 & HO-pGPD-mito-roGFP-KanMX6-HO & (Liao et al., 2020a) \\
\hline & pOM13 & Euroscarf, P30388 \\
\hline & pSH62 & Euroscarf, P30120 \\
\hline
\end{tabular}

\section{Primers used in this study:}

\begin{tabular}{|c|c|c|}
\hline Purpose & $\begin{array}{l}\text { Primer } \\
\text { name }\end{array}$ & Primer sequence \\
\hline \multirow{2}{*}{$\begin{array}{l}\text { C-terminal } \\
\text { tagging Mfb1p } \\
\text { with a GG linker } \\
\text { using pFA6a } \\
\text { vector }\end{array}$} & RD003-F & $\begin{array}{l}\text { TGTAATCAAACGGCTTGACGCTAATACCGATTTTAATATAGG } \\
\text { AGGTGGTGACGGTGCTGGTTTAATTAAC }\end{array}$ \\
\hline & WP066-R & $\begin{array}{l}\text { CGTATAGTAGCTCTTTTTTTGTATCGATTTATAAAAATGCGAA } \\
\text { TTCGAGCTCGTTTAAAC }\end{array}$ \\
\hline $\begin{array}{l}\text { C-terminal } \\
\text { tagging Cit1p }\end{array}$ & RHP392-F & $\begin{array}{l}\text { AAAATACAAGGAGTTGGTAAAGAAAATCGAAAGTAAGAACC } \\
\text { GGTGACGGTGCTGGTTTA }\end{array}$ \\
\hline
\end{tabular}




\begin{tabular}{|c|c|c|}
\hline $\begin{array}{l}\text { with mCherry } \\
\text { using pCY3909- } \\
02\end{array}$ & RHP393-R & $\begin{array}{l}\text { TTTGAATAGTCGCATACCCTGAATCAAAAATCAAATTTTCCCA } \\
\text { TCGATGAATTCGAGCTCG }\end{array}$ \\
\hline \multirow{2}{*}{$\begin{array}{l}\text { Knocking out } \\
\text { BUD1 (pOM) }\end{array}$} & MP316-F & $\begin{array}{l}\text { TCTATCATCGCTTAGAAATATTTGGCTAGGAAACATTAGGTG } \\
\text { CAGGTCGACAACCCTTAAT }\end{array}$ \\
\hline & MP317-R & $\begin{array}{l}\text { TTATCTGATATCTTGATTCATTTATAATAAAATTAAGTGACTG } \\
\text { CAGCGTACGGATATCACCTA }\end{array}$ \\
\hline \multirow{2}{*}{$\begin{array}{l}\text { Checking bud1 } \\
\text { knock-outs }\end{array}$} & MP318-F & TACATACAACGTTCTAATATTTTGG \\
\hline & MP319-R & AAACCTTTTAGAACTATAATAAAAC \\
\hline \multirow{2}{*}{$\begin{array}{l}\text { Knocking out } \\
\text { MFB1 }\end{array}$} & MP005-F & $\begin{array}{l}\text { CCAACACAGTCTTCATACACTATTATTATTCATTTTATGGACG } \\
\text { CTGCAGGTCGACAACCC }\end{array}$ \\
\hline & MP006-R & $\begin{array}{l}\text { CGTATAGTAGCTCTTTTTTTGTATCGATTTATAAAAATGCTTA } \\
\text { AGGGTTCTCGAGAGCTC }\end{array}$ \\
\hline \multirow{2}{*}{$\begin{array}{l}\text { Checking } m f b 1 \\
\text { knock-outs }\end{array}$} & MP003-F & CGAATCTTCTTAATGAAATAGCAGAAGTGC \\
\hline & MP004-R & ATCTCTGCTGAGAGTATGTTGTTCAAGAG \\
\hline \multirow{2}{*}{$\begin{array}{l}\text { Integrated mito- } \\
\text { roGFP to } \mathrm{HO} \\
\text { locus }\end{array}$} & E306-F & GCCGCCAGCTGAAGCTTAATTAT \\
\hline & E307-R & CATAGGCCACTGTAAGATTCCGCC \\
\hline
\end{tabular}




\section{STAR+METHODS KEY RESOURCES TABLE}

\begin{tabular}{|c|c|c|c|}
\hline REAGENT or RESOURCE & SOURCE & IDENTIFIER & RRID \\
\hline \multicolumn{4}{|c|}{ Chemicals, Peptides, and Recombinant proteins } \\
\hline KAPA HiFi PCR kit & $\begin{array}{l}\text { Roche Sequencing and Life } \\
\text { Science, Kapa Biosystems, } \\
\text { Wilmington, MA }\end{array}$ & KK1006 & \\
\hline Hygromycin B & Sigma-Aldrich, St. Louis, MO & $\mathrm{H} 3274$ & \\
\hline Geneticin & Sigma-Aldrich, St. Louis, MO & A1720 & \\
\hline $\begin{array}{l}\text { Calcofluor }{ }^{\circledR} \text { White M2R } \\
\text { staining }\end{array}$ & $\begin{array}{l}\text { Milipore Sigma, Burlington, } \\
\text { MA }\end{array}$ & \#18909 & \\
\hline $\begin{array}{l}\text { Wheat Germ Agglutinin, Alexa } \\
\text { Fluor }{ }^{\mathrm{TM}} 488 \text { Conjugate }\end{array}$ & $\begin{array}{l}\text { Thermo Fisher Scientific, } \\
\text { Waltham, MA }\end{array}$ & \#W11261 & \\
\hline $\begin{array}{l}\text { Wheat Germ Agglutinin, Alexa } \\
\text { Fluor }{ }^{\mathrm{TM}} 594 \text { Conjugate }\end{array}$ & $\begin{array}{l}\text { Thermo Fisher Scientific, } \\
\text { Waltham, MA }\end{array}$ & \#W11262 & \\
\hline $\begin{array}{l}\text { Wheat Germ Agglutinin, Alexa } \\
\text { Fluor }{ }^{\mathrm{TM}} 647 \text { Conjugate }\end{array}$ & $\begin{array}{l}\text { Thermo Fisher Scientific, } \\
\text { Waltham, MA }\end{array}$ & \#W32466 & \\
\hline EZ Link Sulfo-NHS-LC-LC-Biotin & $\begin{array}{l}\text { Thermo Fisher Scientific, } \\
\text { Waltham, MA }\end{array}$ & \#21338 & \\
\hline $\begin{array}{l}\text { Miltenyi } \mu \text { MACs Streptavidin } \\
\text { MicroBeads }\end{array}$ & $\begin{array}{l}\text { Miltenyi Biotec Inc., Auburn, } \\
\text { CA }\end{array}$ & $\# 130-048-101$ & \\
\hline Miltenyi LS Columns & $\begin{array}{l}\text { Miltenyi Biotec Inc., Auburn, } \\
\text { CA }\end{array}$ & $\# 130-042-401$ & \\
\hline Miltenyi MultiStand & $\begin{array}{l}\text { Miltenyi Biotec Inc., Auburn, } \\
\text { CA }\end{array}$ & $\# 130-042-303$ & \\
\hline $\begin{array}{l}\text { Miniature chemostat aging } \\
\text { device (mCAD) }\end{array}$ & (Hendrickson et al., 2018) & & \\
\hline $\begin{array}{l}\text { Dynabeads MyOne } \\
\text { Streptavidin C1 beads }\end{array}$ & $\begin{array}{l}\text { Thermo Fisher Scientific, } \\
\text { Waltham, MA }\end{array}$ & $\# 65001$ & \\
\hline \multicolumn{4}{|c|}{ Experimental Models: Organisms/Strains } \\
\hline \multicolumn{4}{|c|}{ Please refer to Supplementary table 1} \\
\hline \multicolumn{4}{|l|}{ Oligonucleotides } \\
\hline \multicolumn{4}{|c|}{ Please refer to Supplementary table 2} \\
\hline \multicolumn{4}{|l|}{ Recombinant DNA } \\
\hline pFA6a-link-GFPEnvy-SpHis5 & $\begin{array}{l}\text { (Slubowski et al., 2015) } \\
\text { Linda Huang lab }\end{array}$ & $\begin{array}{l}\text { Addgene plasmid } \\
\# 60782\end{array}$ & Addgene_60782 \\
\hline pCY3090-02 & $\begin{array}{l}\text { (Young et al., 2012) } \\
\text { Anne Robinson lab }\end{array}$ & $\begin{array}{l}\text { Addgene plasmid } \\
\# 36231\end{array}$ & Addgene_36231 \\
\hline pFA6a-GFP(S65T)-KanMX6 & $\begin{array}{l}\text { (Bähler et al., 1998) } \\
\text { Jurg Bahler and John Pringle } \\
\text { lab }\end{array}$ & $\begin{array}{l}\text { Addgene plasmid } \\
\# 39292\end{array}$ & Addgene_39292 \\
\hline $\begin{array}{l}\text { HO-pGPD-mito-roGFP- } \\
\text { KanMX6-HO }\end{array}$ & (Liao et al., 2020b) & & \\
\hline pOM13 & $\begin{array}{l}\text { (Gauss et al., 2005), } \\
\text { Euroscarf }\end{array}$ & $\begin{array}{l}\text { Euroscarf plasmid } \\
\text { \#P30388 }\end{array}$ & \\
\hline
\end{tabular}


bioRxiv preprint doi: https://doi.org/10.1101/2021.09.30.462607; this version posted September 30, 2021. The copyright holder for this preprint (which was not certified by peer review) is the author/funder, who has granted bioRxiv a license to display the preprint in perpetuity. It is made available under aCC-BY-NC-ND 4.0 International license.

\begin{tabular}{|l|l|l|l|}
\hline pSH62 & $\begin{array}{l}\text { (Gueldener et al., 2002), } \\
\text { Euroscarf }\end{array}$ & $\begin{array}{l}\text { Euroscarf plasmid } \\
\# \text { P30120 }\end{array}$ & \\
\hline Software and Algorithms & Quorum Technologies & $\begin{array}{l}\text { https://www.quor } \\
\text { umtechnologies.c } \\
\text { om/ } \\
\text { volocity/volocity- } \\
\text { downloads/legacy }\end{array}$ & \\
\hline Volocity 6.3 & (Schindelin et al., 2012) & $\begin{array}{l}\text { https://imagej.net } \\
\text { /Fiji }\end{array}$ & SCR_002285 \\
\hline Coloc2 & $\begin{array}{l}\text { Daniel James White, Tom } \\
\text { Kazimiers, Ellen Dobson }\end{array}$ & $\begin{array}{l}\text { hol//imagej.net } \\
\text { /Coloc 2 }\end{array}$ & \\
\hline GraphPad Prism7 & GraphPad & $\begin{array}{l}\text { https://www.grap } \\
\text { hpad.com/scientifi } \\
\text { c-software/prism/ }\end{array}$ & SCR_002798 \\
\hline
\end{tabular}




\section{References}

Bähler, J., Wu, J.Q., Longtine, M.S., Shah, N.G., Mckenzie, A., III, Steever, A.B., Wach, A., Philippsen, P., Pringle, J.R., 1998. Heterologous modules for efficient and versatile PCRbased gene targeting in Schizosaccharomyces pombe. Yeast 14, 943-951. doi:10.1002/(SICI)1097-0061(199807)14:10<943::AID-YEA292>3.0.CO;2-Y

Bi, E., Park, H.-O., 2012. Cell Polarization and Cytokinesis in Budding Yeast. Genetics 191, 347-387. doi:10.1534/genetics.111.132886

Budovsky, A., Fraifeld, V.E., Aronov, S., 2011. Linking cell polarity, aging and rejuvenation. Biogerontology 12, 167-175. doi:10.1007/s10522-010-9305-4

Campos, S.E., Avelar-Rivas, J.A., Garay, E., Juárez-Reyes, A., DeLuna, A., 2018. Genomewide mechanisms of chronological longevity by dietary restriction in budding yeast. Aging Cell 17, e12749. doi:10.1111/acel.12749

Carolina Florian, M., Geiger, H., 2010. Concise Review: Polarity in Stem Cells, Disease, and Aging. STEM CELLS 28, 1623-1629. doi:10.1002/stem.481

Chant, J., Pringle, J.R., 1995. Patterns of bud-site selection in the yeast Saccharomyces cerevisiae. J Cell Biol 129, 751-765. doi:10.1083/jcb.129.3.751

Chant, J., Pringle, J.R., 1991. Budding and cell polarity in Saccharomyces cerevisiae. Current Opinion in Genetics \& Development 1, 342-350. doi:10.1016/s0959-437x(05)80298-9

Chiou, J.-G., Balasubramanian, M.K., Lew, D.J., 2017. Cell Polarity in Yeast. Annu. Rev. Cell Dev. Biol. 33, 77-101. doi:10.1146/annurev-cellbio-100616-060856

Clay, L., Caudron, F., Denoth Lippuner, A., Boettcher, B., Buvelot Frei, S., Snapp, E.L., Barral, Y., 2014. A sphingolipid-dependent diffusion barrier confines ER stress to the yeast mother cell. eLife 3, e01883. doi:10.7554/eLife.01883

Dürr, M., Escobar-Henriques, M., Merz, S., Geimer, S., Langer, T., Westermann, B., 2006. Nonredundant roles of mitochondria-associated F-box proteins Mfb1 and Mdm30 in maintenance of mitochondrial morphology in yeast. Molecular Biology of the Cell 17, 37453755. doi:10.1091/mbc.e06-01-0053

Erjavec, N., Cvijovic, M., Klipp, E., Nyström, T., 2008. Selective benefits of damage partitioning in unicellular systems and its effects on aging. Proc. Natl. Acad. Sci. U.S.A. 105, 1876418769. doi:10.1073/pnas.0804550105

Fehrenbacher, K.L., Yang, H.-C., Gay, A.C., Huckaba, T.M., Pon, L.A., 2004. Live cell imaging of mitochondrial movement along actin cables in budding yeast. Curr. Biol. 14, 1996-2004. doi:10.1016/j.cub.2004.11.004

Florian, M.C., Dörr, K., Niebel, A., Daria, D., Schrezenmeier, H., Rojewski, M., Filippi, M.-D., Hasenberg, A., Gunzer, M., Scharffetter-Kochanek, K., Zheng, Y., Geiger, H., 2012. Cdc42 activity regulates hematopoietic stem cell aging and rejuvenation. Cell Stem Cell 10, 520 530. doi:10.1016/j.stem.2012.04.007

Florian, M.C., Klose, M., Sacma, M., Jablanovic, J., Knudson, L., Nattamai, K.J., Marka, G., Vollmer, A., Soller, K., Sakk, V., Cabezas-Wallscheid, N., Zheng, Y., Mulaw, M.A., Glauche, I., Geiger, H., 2018. Aging alters the epigenetic asymmetry of HSC division. Plos Biol 16, e2003389. doi:10.1371/journal.pbio.2003389

Gardner, J.M., Jaspersen, S.L., 2014. Manipulating the Yeast Genome: Deletion, Mutation, and Tagging by PCR, in: Ubiquitin Family Modifiers and the Proteasome, Methods in Molecular Biology. Springer New York, New York, NY, pp. 45-78. doi:10.1007/978-1-4939-1363-3_5

Gauss, R., Trautwein, M., Sommer, T., Spang, A., 2005. New modules for the repeated internal and N-terminal epitope tagging of genes in Saccharomyces cerevisiae. Yeast 22, 1-12. doi:10.1002/yea.1187 
Gietz, R.D., Woods, R.A., 2002. Transformation of yeast by lithium acetate/single-stranded carrier DNA/polyethylene glycol method. Meth. Enzymol. 350, 87-96. doi:10.1016/s00766879(02)50957-5

Gueldener, U., Heinisch, J., Koehler, G.J., Voss, D., Hegemann, J.H., 2002. A second set of loxP marker cassettes for Cre-mediated multiple gene knockouts in budding yeast. Nucleic Acids Research 30, e23-23. doi:10.1093/nar/30.6.e23

Hendrickson, D.G., Soifer, I., Wranik, B.J., Kim, G., Robles, M., Gibney, P.A., Mclsaac, R.S., 2018. A new experimental platform facilitates assessment of the transcriptional and chromatin landscapes of aging yeast. eLife 7, pdb.prot4169. doi:10.7554/eLife.39911

Higuchi, R., Vevea, J.D., Swayne, T.C., Chojnowski, R., Hill, V., Boldogh, I.R., Pon, L.A., 2013. Actin dynamics affect mitochondrial quality control and aging in budding yeast. Curr. Biol. 23, 2417-2422. doi:10.1016/j.cub.2013.10.022

Jazwinski, S.M., Kim, S., Lai, C.Y., Benguria, A., 1998. Epigenetic stratification: the role of individual change in the biological aging process. Exp. Gerontol. 33, 571-580. doi:10.1016/s0531-5565(98)00029-1

Kang, P.J., Angerman, E., Nakashima, K., Pringle, J.R., Park, H.-O., 2004. Interactions among Rax1p, Rax2p, Bud8p, and Bud9p in marking cortical sites for bipolar bud-site selection in yeast. Molecular Biology of the Cell 15, 5145-5157. doi:10.1091/mbc.e04-07-0600

Kennedy, B.K., Austriaco, N.R., Guarente, L., 1994. Daughter cells of Saccharomyces cerevisiae from old mothers display a reduced life span. J Cell Biol 127, 1985-1993. doi:10.1083/jcb.127.6.1985

Kondo-Okamoto, N., Ohkuni, K., Kitagawa, K., McCaffery, J.M., Shaw, J.M., Okamoto, K., 2006. The novel F-box protein $\mathrm{Mfb} 1 \mathrm{p}$ regulates mitochondrial connectivity and exhibits asymmetric localization in yeast. Molecular Biology of the Cell 17, 3756-3767. doi:10.1091/mbc.e06-02-0145

Liao, P.-C., Franco-lborra, S., Yang, Y., Pon, L.A., 2020a. Live cell imaging of mitochondrial redox state in mammalian cells and yeast. Methods Cell Biol 155, 295-319. doi:10.1016/bs.mcb.2019.11.008

Liao, P.-C., Yang, E.J., Pon, L.A., 2020b. Live-Cell Imaging of Mitochondrial Redox State in Yeast Cells. STAR Protoc 1, 100160. doi:10.1016/j.xpro.2020.100160

Lindstrom, D.L., Gottschling, D.E., 2009. The mother enrichment program: a genetic system for facile replicative life span analysis in Saccharomyces cerevisiae. Genetics 183, 413-221SI-13SI. doi:10.1534/genetics.109.106229

Longo, V.D., Shadel, G.S., Kaeberlein, M., Kennedy, B., 2012. Replicative and Chronological Aging in Saccharomyces cerevisiae. Cell Metabolism 16, 18-31. doi:10.1016/j.cmet.2012.06.002

Manzano-López, J., Matellán, L., Álvarez-Llamas, A., Blanco-Mira, J.C., Monje-Casas, F., 2019. Asymmetric inheritance of spindle microtubule- organizing centres preserves replicative lifespan. Nature Cell Biology 1-18. doi:10.1038/s41556-019-0364-8

Maxwell, C.S., Magwene, P.M., 2017. The quick and the dead: microbial demography at the yeast thermal limit. Mol. Ecol. 26, 1631-1640. doi:10.1111/mec.13955

McFaline-Figueroa, J.R., Vevea, J., Swayne, T.C., Zhou, C., Liu, C., Leung, G., Boldogh, I.R., Pon, L.A., 2011. Mitochondrial quality control during inheritance is associated with lifespan and mother-daughter age asymmetry in budding yeast. Aging Cell 10, 885-895. doi:10.1111/j.1474-9726.2011.00731.x

Moseley, J.B., Goode, B.L., 2006. The yeast actin cytoskeleton: from cellular function to biochemical mechanism. Microbiol. Mol. Biol. Rev. 70, 605-645. doi:10.1128/MMBR.0001306

Pernice, W.M., Vevea, J.D., Pon, L.A., 2016. A role for Mfb1p in region-specific anchorage of high-functioning mitochondria and lifespan in Saccharomyces cerevisiae. Nat Commun 7, 10595. doi:10.1038/ncomms10595 
Schindelin, J., Arganda-Carreras, I., Frise, E., Kaynig, V., Longair, M., Pietzsch, T., Preibisch, S., Rueden, C., Saalfeld, S., Schmid, B., Tinevez, J.-Y., White, D.J., Hartenstein, V., Eliceiri, K., Tomancak, P., Cardona, A., 2012. Fiji: an open-source platform for biological-image analysis. Nat Meth 9, 676-682. doi:10.1038/nmeth.2019

Shepard, K.A., Gerber, A.P., Jambhekar, A., Takizawa, P.A., Brown, P.O., Herschlag, D., DeRisi, J.L., Vale, R.D., 2003. Widespread cytoplasmic mRNA transport in yeast: identification of 22 bud-localized transcripts using DNA microarray analysis. Proceedings of the National Academy of Sciences 100, 11429-11434. doi:10.1073/pnas.2033246100

Sherman, F., 2002. Getting started with yeast. Meth. Enzymol. 350, 3-41. doi:10.1016/S00766879(02)50954-X

Sinclair, D.A., Mills, K., Guarente, L., 1997. Accelerated aging and nucleolar fragmentation in yeast sgs1 mutants. Science 277, 1313-1316. doi:10.1126/science.277.5330.1313

Slaughter, B.D., Smith, S.E., Li, R., 2009. Symmetry Breaking in the Life Cycle of the Budding Yeast. Cold Spring Harbor Perspectives in Biology 1, a003384-a003384. doi:10.1101/cshperspect.a003384

Slubowski, C.J., Funk, A.D., Roesner, J.M., Paulissen, S.M., Huang, L.S., 2015. Plasmids for Cterminal tagging in Saccharomyces cerevisiae that contain improved GFP proteins, Envy and Ivy. Yeast 32, 379-387. doi:10.1002/yea.3065

Smeal, T., Claus, J., Kennedy, B., Cole, F., Guarente, L., 1996. Loss of transcriptional silencing causes sterility in old mother cells of $S$. cerevisiae. Cell 84, 633-642. doi:10.1016/s00928674(00)81038-7

Soares, H., Marinho, H.S., Real, C., Antunes, F., 2013. Cellular polarity in aging: role of redox regulation and nutrition. Genes Nutr 9, 1083-17. doi:10.1007/s12263-013-0371-5

Swayne, T.C., Zhou, C., Boldogh, I.R., Charalel, J.K., McFaline-Figueroa, J.R., Thoms, S., Yang, C., Leung, G., Mclnnes, J., Erdmann, R., Pon, L.A., 2011. Role for cER and Mmr1p in anchorage of mitochondria at sites of polarized surface growth in budding yeast. Curr. Biol. 21, 1994-1999. doi:10.1016/j.cub.2011.10.019

Vevea, J.D., Wolken, D.M.A., Swayne, T.C., White, A.B., Pon, L.A., 2013. Ratiometric biosensors that measure mitochondrial redox state and ATP in living yeast cells. J Vis Exp e50633-e50633. doi:10.3791/50633

Wang, Y., Lo, W.-C., Chou, C.-S., 2017. A modeling study of budding yeast colony formation and its relationship to budding pattern and aging. PLoS Comput Biol 13, e1005843-23. doi:10.1371/journal.pcbi.1005843

Wu, C.-F., Lew, D.J., 2013. Beyond symmetry-breaking: competition and negative feedback in GTPase regulation. Trends in Cell Biology 23, 476-483. doi:10.1016/j.tcb.2013.05.003

Yang, H.C., Palazzo, A., Swayne, T.C., Pon, L.A., 1999. A retention mechanism for distribution of mitochondria during cell division in budding yeast. Curr. Biol. 9, 1111-1114. doi:10.1016/s0960-9822(99)80480-1

Young, C.L., Raden, D.L., Caplan, J.L., Czymmek, K.J., Robinson, A.S., 2012. Cassette series designed for live-cell imaging of proteins and high-resolution techniques in yeast. Yeast 29, 119-136. doi:10.1002/yea.2895

Zheng, Y., Bender, A., Cerione, R.A., 1995. Interactions among proteins involved in bud-site selection and bud-site assembly in Saccharomyces cerevisiae. J. Biol. Chem. 270, 626630. doi:10.1074/jbc.270.2.626 